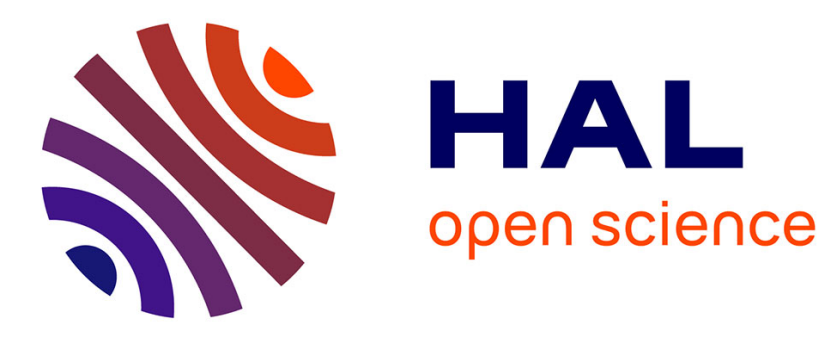

\title{
Spectroscopy of Tm3+-doped CaF2 waveguiding thin films grown by Liquid Phase Epitaxy
}

\author{
Pavel Loiko, Gurvan Brasse, Liza Basyrova, Abdelmjid Benayad, Jean-Louis \\ Doualan, Cesare Meroni, A. Braud, Elena Dunina, Alexey Kornienko, Mikhail \\ Baranov, et al.
}

\section{To cite this version:}

Pavel Loiko, Gurvan Brasse, Liza Basyrova, Abdelmjid Benayad, Jean-Louis Doualan, et al.. Spectroscopy of Tm3+-doped CaF2 waveguiding thin films grown by Liquid Phase Epitaxy. Journal of Luminescence, 2021, 238, pp.118109. 10.1016/j.jlumin.2021.118109 . hal-03345688

\section{HAL Id: hal-03345688 \\ https://hal.science/hal-03345688}

Submitted on 7 Oct 2021

HAL is a multi-disciplinary open access archive for the deposit and dissemination of scientific research documents, whether they are published or not. The documents may come from teaching and research institutions in France or abroad, or from public or private research centers.
L'archive ouverte pluridisciplinaire HAL, est destinée au dépôt et à la diffusion de documents scientifiques de niveau recherche, publiés ou non, émanant des établissements d'enseignement et de recherche français ou étrangers, des laboratoires publics ou privés. 


\title{
Spectroscopy of $\mathrm{Tm}^{3+}$-doped $\mathrm{CaF}_{2}$ waveguiding thin films grown by Liquid Phase Epitaxy
}

Pavel Loiko ${ }^{a}$, Gurvan Brasse ${ }^{\mathrm{a}}$, Liza Basyrova ${ }^{\mathrm{a}}$, Abdelmjid Benayad ${ }^{\mathrm{a}}$, Jean-Louis Doualan ${ }^{\mathrm{a}}$, Cesare Meroni $^{\mathrm{a}}$, Alain Braud ${ }^{\mathrm{a}}$, Elena Dunina ${ }^{\mathrm{b}}$, Alexey Kornienko ${ }^{\mathrm{b}}$, Mikhail Baranov ${ }^{\mathrm{c}}$, Gozhalskii Daniil $^{\mathrm{c}}$, and Patrice Camy ${ }^{\mathrm{a}, *}$

${ }^{a}$ Centre de recherche sur les Ions, les Matériaux et la Photonique (CIMAP), UMR 6252 CEA-CNRS-ENSICAEN, Université de Caen Normandie, 6 Boulevard du Maréchal Juin, 14050 Caen Cedex 4, France

${ }^{b}$ Vitebsk State Technological University, 72 Moskovskaya Ave., 210035 Vitebsk, Belarus 'ITMO University, 49 Kronverkskiy Pr., 197101 Saint-Petersburg, Russia

*Corresponding author,e-mail: patrice.camy@ensicaen.fr

\begin{abstract}
Thulium-doped calcium fluoride ( $\left.\mathrm{Tm}: \mathrm{CaF}_{2}\right)$ single-crystalline films are grown on (100)-oriented undoped bulk $\mathrm{CaF}_{2}$ substrates by Liquid Phase Epitaxy (LPE) using LiF as a solvent. Their spectroscopic properties are studied in details. For $\sim 2$ at.\% Tm-doped films, the active ions are predominantly isolated and are located in oxygen-assisted trigonal sites, $\mathrm{C}_{3 \mathrm{v}}\left(\mathrm{T}_{2}\right)$. With increasing the Tm doping level, ion clustering is promoted but it is slowed down as compared to bulk crystals. For $\sim 6$ at.\% Tm-doped films, the majority of active ions form clusters resulting in a "glassy-like" spectroscopic behavior (smooth and broad spectral bands). For such layers, the maximum stimulated-emission cross-section for the ${ }^{3} \mathrm{~F}_{4} \rightarrow{ }^{3} \mathrm{H}_{6}$ transition is $0.14 \times 10^{-20} \mathrm{~cm}^{2}$ at $1856 \mathrm{~nm}$, the luminescence lifetime of the ${ }^{3} \mathrm{~F}_{4}$ state is $21.70 \mathrm{~ms}$ and the emission bandwidth exceeds $180 \mathrm{~nm}$. The transition probabilities of $\mathrm{Tm}^{3+}$ ions are determined using the Judd-Ofelt theory. The waveguiding properties of the $\mathrm{Tm}: \mathrm{CaF}_{2}$ films are confirmed. Highly-doped $\mathrm{Tm}: \mathrm{CaF}_{2}$ epitaxial films are promising for waveguide lasers at $\sim 2 \mu \mathrm{m}$.
\end{abstract}

Keywords: Liquid phase epitaxy; calcium fluoride; thulium ions; Raman spectra; optical spectroscopy; luminescence. 


\section{Introduction}

Thulium ions $\left(\mathrm{Tm}^{3+}\right)$ are attractive for laser emission in the eye-safe spectral range of $\sim 2$ $\mu \mathrm{m}$ owing to the ${ }^{3} \mathrm{~F}_{4} \rightarrow{ }^{3} \mathrm{H}_{6} 4 \mathrm{f}-4 \mathrm{f}$ transition [1]. Due to the large Stark splitting of the groundstate $\left({ }^{3} \mathrm{H}_{6}\right), \mathrm{Tm}^{3+}$-doped materials exhibit broad spectral bands making them attractive for broadly tunable [2] and mode-locked lasers [3]. $\mathrm{Tm}^{3+}$ ions can be easily excited at $\sim 0.8 \mu \mathrm{m}$, e.g., by AlGaAs laser diodes [4]. Owing to the efficient cross-relaxation (CR) process for neighboring $\mathrm{Tm}^{3+}$ ions, this pump scheme can lead to a quantum efficiency of 2 (one-for-two process) [5]. Tm lasers are of interest for molecular spectroscopy, range-finding, soft material processing, medicine and further frequency conversion into mid-IR.

Tm waveguide lasers benefit from compact design, small mode areas leading to low laser thresholds and high intracavity intensity and they are promising for sensing applications. So far, Liquid Phase Epitaxy (LPE) was recognized as a powerful method to fabricate singlecrystalline oriented $\mathrm{Tm}^{3+}$-doped active layers [6-8] exhibiting high optical quality and low propagation losses (down to $0.1 \mathrm{~dB} / \mathrm{cm}$ ) [9]. Tm ${ }^{3+}$-doped LPE films can be used in the planar waveguide geometry or, after an additional microstructuring step [5,10], in the channel one. So far, laser-active $\mathrm{Tm}^{3+}$-doped single-crystalline films based on oxide $[6,8,9]$ and fluoride [10] materials were fabricated.

Among the host matrices for $\mathrm{Tm}^{3+}$ doping, fluoride crystals attracted a lot of attention [11-14]. This is because of a combination of their good thermal and spectroscopic properties. Calcium fluoride $\left(\mathrm{CaF}_{2}\right)$ is one example. As a host matrix, it provides high thermal conductivity $\left(\sim 9.7 \mathrm{Wm}^{-1} \mathrm{~K}^{-1}\right)$ [15], isotropic thermal expansion, broadband transparency and low refractive index [16]. When doped with $\mathrm{Tm}^{3+}$ ions, it exhibits smooth and broad spectral bands (a "glassylike" behavior), long upper-laser-level $\left({ }^{3} \mathrm{~F}_{4}\right)$ lifetime and efficient CR [1]. This spectroscopic behavior is due to the strong clustering of active ions resulting in inhomogeneous broadening of spectral bands [17]. So far, efficient bulk Tm:CaF2 lasers were demonstrated [18,19].

$\mathrm{CaF}_{2}$ appears as an attractive material for waveguide applications. Its growth process by the Czochralski method is well-developed [20] and undoped oriented substrates are well available at reasonable costs (note that $\mathrm{CaF}_{2}$ is a widely-used material for optical components). $\mathrm{CaF}_{2}$ can be doped with rare-earth ions $\left(\mathrm{RE}^{3+}\right)$ up to relatively high concentrations which is accompanied by an increase of the refractive index [21], so that $\mathrm{RE}^{3+}: \mathrm{CaF}_{2} / \mathrm{CaF}_{2}$ homoepitaxies show light guiding [22]. The isotropic and attractive thermal properties of $\mathrm{CaF}_{2}$ alleviate the thermal effects.

However, so far, the homoepitaxial growth of $\mathrm{RE}^{3+}$-doped $\mathrm{CaF}_{2}$ films has not been deeply studied. In the early studies, undoped $\mathrm{CaF}_{2}$ films were grown on semiconducting substrates (e.g., (100) or (111) oriented Si (mainly), GaAs or InP) by molecular beam epitaxy (MBE) [2325]. The selection of silicon was because of the relatively close lattice constants of $\mathrm{Si}$ and $\mathrm{CaF}_{2}$, so that the latter was used as a buffer layer for further deposition steps. Later on, $\mathrm{RE}^{3+}: \mathrm{CaF}_{2}$ films (where $\mathrm{RE}=\mathrm{Nd}, \mathrm{Er}, \mathrm{Yb}$ or $\mathrm{Pr}$ ) were grown on (100) oriented $\mathrm{CaF}_{2}$ substrates also by MBE [26-29]. However, the grown layers had a thickness of only few $\mu \mathrm{m}$. The LPE growth of $\mathrm{Yb}^{3+}$ - and $\mathrm{Tm}^{3+}$-doped $\mathrm{CaF}_{2}$ layers was first reported in [30,31] and first laser operation was achieved in $\mathrm{Yb}: \mathrm{CaF}_{2}$ thin-films in the planar waveguide geometry [22]. 
Very recently, we reported on the LPE growth of high-optical quality $\mathrm{Tm}: \mathrm{CaF}_{2}$ layers with a thickness up to $\sim 100 \mu \mathrm{m}$ and a doping level up to $\sim 6$ at. $\%$ by LPE using lithium fluoride $(\mathrm{LiF})$ as a solvent [32]. As compared to earlier studies where $\mathrm{CaCl}_{2}$ was used for the same purpose [30,31], $\mathrm{LiF}$ is less corrosive that helps to preserve the integrity of metallic parts of the growth set-up, and it is less hygroscopic. In the present work, we report on the detailed spectroscopic study of LPE-grown Tm: $\mathrm{CaF}_{2}$ films and, in particular, we focus on the effect of Tm doping level on the preferable site symmetry for active ions in such films that greatly affects their emission properties.

\section{Growth of single-crystalline films}

Single-crystalline $\mathrm{Tm}^{3+}$-doped calcium fluoride $\left(\mathrm{CaF}_{2}\right)$ thin-films were grown on oriented undoped bulk $\mathrm{CaF}_{2}$ substrates by Liquid Phase Epitaxy using lithium fluoride $(\mathrm{LiF})$ as a solvent [32]. The molar composition of $65 \% \mathrm{LiF}-(35-x) \% \mathrm{CaF}_{2}-x \% \mathrm{TmF}_{3}$ was used. The starting reagents were $\mathrm{LiF}$ (purity: >99.5\%), $\mathrm{CaF}_{2}(99.5 \%)$ and $\mathrm{Tm}_{2} \mathrm{O}_{3}(4 \mathrm{~N}) . \mathrm{TmF}_{3}$ was achieved by fluorination of the $\mathrm{Tm}_{2} \mathrm{O}_{3}$ precursor. Two initial compositions with $x=5 \mathrm{~mol} \%$ and $1.67 \mathrm{~mol} \%$ were studied. The substrates were cut from high optical grade undoped $\mathrm{CaF}_{2}$ wafers (Crystran, Ltd) with their surface oriented along the (100) crystallographic plane. They had a thickness of $2.0 \mathrm{~mm}$ and lateral dimensions of $\sim 10 \times 30 \mathrm{~mm}^{2}$. Both surfaces of the substrates were polished to laser-grade quality. We have selected this substrate orientation to facilitate the LPE process in analogy to the growth of bulk $\mathrm{CaF}_{2}$ crystals for which the preferred growth direction is along the [100] direction. In previous studies of molecular beam epitaxy of rare-earth doped $\mathrm{CaF}_{2}$ films, particularly (100) oriented $\mathrm{CaF}_{2}$ substrates were also used [21].

For the LPE growth, the raw materials were weighted according to the molar composition and well mixed. The batch was placed in a glassy carbon crucible which was then heated up to $900{ }^{\circ} \mathrm{C}$ and kept at this temperature for several hours under mechanical stirring leading to homogenization of the melt. The experimental saturation temperature was in the range of 854 $856{ }^{\circ} \mathrm{C}$ (for $x=5 \mathrm{~mol} \%$ ) and $820^{\circ} \mathrm{C}$ with a step cooling to $815^{\circ} \mathrm{C}$ at a rate of $2{ }^{\circ} \mathrm{C} / \mathrm{min}$ (for $x$ $=1.75 \mathrm{~mol} \%)$. The substrate was dipped almost vertically in the molten bath and rotated at a rate of 10 revolutions per minute (r.p.m.). The growth duration was $45 \mathrm{~min}(x=5 \mathrm{~mol} \%)$ or 70 $\min (x=1.75 \mathrm{~mol} \%)$ resulting in a measured film thickness of up to $85 \mu \mathrm{m}$ (depending on the sample). To avoid the formation of unwanted (translucent) oxyfluoride phase, the growth chamber was sealed to a good secondary vacuum $\left(\sim 10^{-6} \mathrm{mbar}\right)$ and filled with Ar. After completing the growth, the epitaxy was removed from the flux and slowly cooled down to room temperature ( $\mathrm{RT}, \sim 20^{\circ} \mathrm{C}$ ).

The as-grown layers were transparent and colorless. On their surface, residual solvent ( $\mathrm{LiF})$ was crystallized during the epitaxy cooling which was easily removed by polishing.

The actual doping concentration of $\mathrm{Tm}^{3+}$ ions (with respect to $\mathrm{Ca}^{2+}$ ) was calculated using the segregation coefficient previously reported [32], $K_{\mathrm{Tm}}=0.40 \pm 0.05$, and it amounted to $\sim 6$ at.\% $\operatorname{Tm}(x=5 \mathrm{~mol} \%)$ and $\sim 2$ at.\% $\operatorname{Tm}(x=1.75 \mathrm{~mol} \%)$.

\section{Experimental}


The morphology of the films was studied using a scanning electron microscope (SEM, MERLIN, Carl Zeiss). This microscope was equipped with an X-max 80 Oxford detector and used for Energy Dispersive X-ray (EDX) analysis of the film composition. A thin ( $27 \mathrm{~nm})$ layer of carbon was deposited on the sample for this aim. The acceleration voltage was $10 \mathrm{keV}$ and the spatial resolution for EDX mapping was $\sim 30 \mathrm{~nm}$.

The optical observation of the polished epitaxy was performed using a confocal scanning laser microscope (LSM 710, Carl Zeiss) equipped with $\times 20$ and $\times 50$ objectives, a blue $\mathrm{GaN}$ laser $(405 \mathrm{~nm})$ and a set of crossed polarizers.

The spectroscopic studies were first performed at RT (293 K). The Raman spectra were measured using a confocal microscope (inVia, Renishaw) equipped with a $\times 50$ objective (Leica) and an $\mathrm{Ar}^{+}$ion laser $(488.0 \mathrm{~nm})$.

The absorption spectra were measured using a spectrophotometer (Lambda 1050, Perkin Elmer). The luminescence excitation spectra around $0.8 \mu \mathrm{m}$ were measured using a tunable Ti:Sapphire laser, a monochromator (HRS2, Jobin-Yvon), a lock-in amplifier (SR810 DSP, Stanford Research Systems) and an InGaAs detector. The luminescence spectra were measured using an optical spectrum analyzer (OSA, Yokogawa AQ6375B) employing a Ti:Sapphire laser tuned to $765 \mathrm{~nm}$ as excitation source. The luminescence decays were detected by using a ns optical parametric oscillator (Horizon, Continuum) as pump source, a 1/4 m monochomator (Oriel 77200), two InGaAs detectors and an $8 \mathrm{GHz}$ digital oscilloscope (DSA70804B, Tektronix).

For low-temperature (LT, $12 \mathrm{~K}$ ) absorption and luminescence studies, the epitaxies were mounted on an APD DE-202 closed-cycle cryo-cooler equipped with an APD HC 2 Helium vacuum cryo-compressor and a Laceshore 330 temperature controller. A silver paint was used for thermal contact between the sample and the holder. The spectral resolution for LT measurements was $0.2 \mathrm{~nm}$.

The waveguiding properties of the Tm: $\mathrm{CaF}_{2}$ film were studied by coupling the light from a Ti:Sapphire laser (3900S, SpectraPhysics) operating in TEM00 mode and tuned to $770 \mathrm{~nm}$. The pump was focused using a spherical $\mathrm{CaF}_{2}$ lens $(\mathrm{f}=40 \mathrm{~mm})$ resulting in a pump spot size of $30 \pm 5 \mu \mathrm{m}$. The guided mode was detected with a CCD camera (BladeCam-XHR, DataRay Inc.) using another $\mathrm{CaF}_{2}$ lens $(\mathrm{f}=15 \mathrm{~mm})$.

\section{Results and Discussion}

\subsection{Film morphology}

The phase purity (cubic, sp. gr. $\mathrm{O}_{\mathrm{h}}^{5}-\mathrm{Fm}^{-} m$, No. 225) of the grown films and their growth direction along the [100] axis was confirmed by single-crystal X-ray diffraction and their low mosaicity - by the reciprocal space mapping, similarly to [32]. For the $\sim 6$ at. $\%$ Tmdoped film, the lattice constant $a_{\text {film }}=5.4806 \AA$ and the relative lattice mismatch $\left|\Delta a / a_{\text {substrate }}\right|$ is $0.15 \%$.

In our previous study [32], we investigated the film morphology only by optical methods. In the present work, we employed SEM for this aim. Typical SEM images of raw (as-grown) top surface of the film doped with $\sim 6$ at.\% Tm are shown in Fig. 1(a-c). In the $\mu \mathrm{m}$-scale, Fig. 1(a), one can see crystalline layers overlaying each other with well-developed rectangular- 
shaped borders, as well as small $(<100 \mathrm{~nm})$ nanocrystallites with squared cross-sections (from the top view) that appear as building blocks of these layers (they are interpreted as crystallization nuclei). This morphology brings to mind the cubic pattern of the natural fluorite. In larger scale, as shown in Fig. 1(b), one can see the smooth surface of the film containing "valleys" with a characteristic size of tens of $\mu \mathrm{m}$ with smooth edges and stepped hills. The residual solvent $(\mathrm{LiF})$ is strongly localized within such "valleys". In larger scale, Fig. 1(c), the surface is like a hilly landscape typical for LPE-grown fluorides [33].

After polishing of the top surface of the film, in some samples, we observed crazing resulting in formation of rectangular-shaped pattern with characteristic dimensions of hundreds of $\mu \mathrm{m}$, Fig. 1(d). This phenomenon seems to be affected by several factors: (i) thickness of the film (it is less probable in thinner films), (ii) Tm doping level (it is more probable in highlydoped films, due to distortion of the crystal lattice and the related mismatch of the lattice parameter with respect to the substrate) and (iii) growth temperature and probably cooling conditions. A very similar pattern was previously observed in $\mathrm{CaF}_{2}$ films grown by molecular beam epitaxy (MBE) on (001) oriented InP substrates [34] and it was related to the change in the lattice mismatch at the growth and room temperatures. In our case, the lattice mismatch is relatively weak and other factors, such as stresses in the film induced by $\mathrm{Tm}^{3+}$ doping, may play a role.

Let us further discuss these observations in light of the previous results on the LPE growth of $\mathrm{CaF}_{2}$. So far, the growth of epitaxial $\mathrm{CaF}_{2}$ films on (111), (110), (100) and (001) oriented substrates (typically, semiconductors, Si or GaAs) was reported [23-25]. Among them, the easiest growth occurs orthogonal to the (111) plane as it corresponds to the minimum free energy [23] and the surface morphology is determined by small triangular hillocks [24] (the (111) plane is the perfect cleavage plane of $\left.\mathrm{CaF}_{2}\right)$. The growth on the (100) oriented substrates is more complicated as films are prone to (111) faceting and columnar growth. However, these undesired effects can be avoided by a proper temperature regime [24,25]. In our case, the use of the same material for the substrate $\left(\mathrm{CaF}_{2}\right)$ reduces the lattice mismatch and eliminates the effect of the thermal expansion difference between the substrate and the layer. Using chemical etching of $\mathrm{CaF}_{2}$ / (100) Si LPE films, Schowalter et al. observed rectangular symmetry of the cracks originating from dislocations and square shape of the pits revealing the (100) symmetry [23] which agrees with our observations. Siskos et al. observed crazing of films grown on (100) GaAs resulting in cross-hatched lines on the surface [35] (the crack directions were identified as projections of the (111) cleavage plane on the substrate surface, i.e., [011] and [011 ${ }^{-}$, as in our case). A similar conclusion was also made in [36] for the growth on (100) Si.

Figure 2 shows a typical SEM image of the end-facet of an epitaxially grown layer of $\sim 6$ at.\% Tm: $\mathrm{CaF}_{2}$ layer, which is relatively thin (thickness: $t=9 \pm 1 \mu \mathrm{m}$ ). It reveals a clear layer / substrate interface and a uniform, single-crystalline and crack-free layer.

The distribution of $\mathrm{Tm}^{3+}$ ions across the layer was analyzed by means of EDX mapping, see Fig. 3. The chemical elements constituting the epitaxy (Ca, F, Tm) were traced across the end-facet resulting in the profiles shown in Fig. 3(a). The analysis allowed us to estimate the thickness of the layer / substrate interface to be $0.4 \pm 0.1 \mu \mathrm{m}$ indicating a weak diffusion of the 
dopant (Tm) into the substrate. The EDX map for Tm, see Fig. 3(b), confirms the uniform distribution of the dopant across the active layer.

The Tm: $\mathrm{CaF}_{2}$ epitaxial films were further studied using confocal laser microscopy in transmission mode, see Fig. 4. A $\sim 6$ at.\% Tm-doped film which exhibited almost no signs of crazing was observed. First, the top surface of the film was only slightly lapped to remove the residual solvent (LiF). It exhibited a hilly landscape topography, Fig. 4(a), similar to that revealed by SEM. After polishing the top surface, Fig. 4(b), the film appeared to be uniform and crack-free (few dark lines originate from the polishing imperfections). Then, the polished end-facet was also observed, Fig. 4(c), revealing a uniform and free of crack layer (thickness: $t$ $=46 \pm 1 \mu \mathrm{m}$ ) with a clear layer / substrate interface. The same area was also observed in crossed polarizers. This approach helps to visualize stresses in the epitaxy. No significant stresses are observed in the layer, except for the area adjacent to the layer/ substrate interface which appears to be brighter thus indicating certain stress.

\subsection{Raman spectra}

For the Raman study, we used the $\sim 6$ at. $\% \mathrm{Tm}: \mathrm{CaF}_{2} / \mathrm{CaF}_{2}$ epitaxy, Fig. 5. The first-order phonon spectrum of undoped $\mathrm{CaF}_{2}$ contains only one Raman-active vibration (symmetry: $\mathrm{T}_{2} \mathrm{~g}$ ) [37]. Indeed, for the substrate, only one line at $\sim 321 \mathrm{~cm}^{-1}$ is observed (its full width at half maximum, FWHM, is $\sim 10 \mathrm{~cm}^{-1}$ ). The spectra of the layer measured from the top and side surfaces are similar and contain the same line at $321 \mathrm{~cm}^{-1}$. With respect to the substrate, the line for the layer is broadened (FWHM $\sim 12 \mathrm{~cm}^{-1}$ ) and reduced in intensity which agrees with the previous observations [38].

Other features are broad bands centered at 157, 285, 371 and $720 \mathrm{~cm}^{-1}$. Russel identified similar bands in the Raman spectra of $\mathrm{CaF}_{2}$ crystals as second-order vibrations [37], however, Gee et al. assigned them to luminescence of impurity rare-earth ions [39]. We assign these bands to the luminescence of the $\mathrm{Tm}^{3+}$ dopant (the ${ }^{1} \mathrm{G}_{4} \rightarrow{ }^{3} \mathrm{H}_{6}$ transition). One may argue that the additional Raman response may originate from the residual LiF. To clarify this, we measured the Raman spectrum of a LiF powder revealing no prominent details except for an extremely weak band at $\sim 630 \mathrm{~cm}^{-1}$ which can be assigned to second-order phonon processes or impurity modes $[40,41]$.

\subsection{Optical absorption}

For absorption studies, we used a $\sim 6$ at. $\% \mathrm{Tm}: \mathrm{CaF}_{2} / \mathrm{CaF}_{2}$ epitaxy (concentration of $\mathrm{Tm}^{3+}$ ions: $N_{\mathrm{Tm}}=8.28 \times 10^{20} \mathrm{~cm}^{-3}$ ). It comprised layers on both sides of the substrate (total thickness: $t=83 \pm 5 \mu \mathrm{m})$.

The RT absorption spectrum, Fig. 6(a), contains $\mathrm{Tm}^{3+}$ ion bands related to transitions from the ground-state $\left({ }^{3} \mathrm{H}_{6}\right)$ to excited-states (from ${ }^{3} \mathrm{~F}_{4}$ to ${ }^{1} \mathrm{D}_{2}$ ). The absorption bands are smooth and broad (a "glassy-like" behavior). To explain it, let us shortly describe the doping mechanism of $\mathrm{CaF}_{2} . \mathrm{Tm}^{3+}$ ions in $\mathrm{CaF}_{2}$ replace $\mathrm{Ca}^{2+}$ cations and an interstitial fluorine anion $\left(\mathrm{F}^{-}\right)$is thus required for charge compensation. At low doping levels $(<0.1$ at. $\%)$ in bulk crystals, the $\mathrm{Tm}^{3+}$ ions are predominantly isolated and there exist several sites with different local symmetries (cubic $-\mathrm{O}_{\mathrm{h}}$, tetragonal $-\mathrm{C}_{4 \mathrm{v}}$ or trigonal $-\mathrm{C}_{3 \mathrm{v}}$ ), depending on the location of the $\mathrm{F}^{-}$ 
anion $[17,42]$. As electric dipole (ED) transitions are forbidden in an undistorted $\mathrm{Oh}_{\mathrm{h}}$ field, the absorption spectra are mainly dominated by transitions of isolated $\mathrm{Tm}^{3+}$ ions in $\mathrm{C}_{3 \mathrm{v}}$ and $\mathrm{C}_{4 \mathrm{v}}$ sites. For even moderate doping levels in bulk crystals ( $>1$ at.\%), $\mathrm{Tm}^{3+}$ ions form clusters [43] leading to significant inhomogeneous broadening of their spectral bands. From the measured absorption spectrum, we suggest that a strong ion clustering is observed in the $\sim 6$ at.\% Tmdoped film.

In Fig. 6(b,c), we focus on the absorption bands corresponding to the ${ }^{3} \mathrm{H}_{6} \rightarrow{ }^{3} \mathrm{H}_{4}$ and ${ }^{3} \mathrm{H}_{6}$ $\rightarrow{ }^{3} \mathrm{~F}_{4}$ transitions and calibrated in terms of absorption cross-sections and compare them with those of bulk Tm:CaF2 crystals with low (0.05 at.\%) and high (4.5 at.\%) doping levels containing predominantly isolated ions and clusters, respectively. The shape of the absorption bands for $\sim 6$ at.\% Tm: $\mathrm{CaF}_{2}$ film resembles that for highly-doped bulk crystal, but they are broadened and reduced in intensity. The difference in spectral shape may be explained by (i) different geometry of clusters, (ii) possible presence of minor fraction of isolated ions and (iii) structure imperfections in thin crystalline layers affecting the local crystal-field. The difference in intensity may originate from the error in the $\mathrm{Tm}^{3+}$ doping concentration.

For the ${ }^{3} \mathrm{H}_{6} \rightarrow{ }^{3} \mathrm{H}_{4}$ pump transition, the maximum absorption cross-section for $\mathrm{Tm}^{3+}$ ions in the film $\sigma_{\text {abs }}$ is $0.29 \times 10^{-20} \mathrm{~cm}^{2}$ at $786 \mathrm{~nm}$ with an absorption bandwidth (FWHM) of $17 \mathrm{~nm}$, compare with $\sigma_{\mathrm{abs}}=0.46 \times 10^{-20} \mathrm{~cm}^{2}$ and $\mathrm{FWHM}=13 \mathrm{~nm}$ for bulk 4.5 at. $\% \mathrm{Tm}: \mathrm{CaF}_{2}$ crystal. For the ${ }^{3} \mathrm{H}_{6} \rightarrow{ }^{3} \mathrm{~F}_{4}$ transition of $\mathrm{Tm}^{3+}$ ions in the film, $\sigma_{\mathrm{abs}}=0.28 \times 10^{-20} \mathrm{~cm}^{2}$ at $1614 \mathrm{~nm}$.

It was difficult to measure directly the absorption spectra of $\sim 2$ at.\% Tm-doped films. Thus, the RT luminescence excitation spectra were detected, Fig. 7. The excitation spectrum for the $\sim 2$ at.\% Tm-doped layer contains a broad and smooth band with a maximum at $768 \mathrm{~nm}$ and a set of narrower lines at longer wavelengths centered at 785, 793, 799 and $805 \mathrm{~nm}$. For the $\sim 6$ at.\% Tm-doped layer, the same spectral features are observed while the relative intensity of the band at $768 \mathrm{~nm}$ greatly increases and the excitation spectrum resembles that for a bulk 4.5 at. $\% \mathrm{Tm}: \mathrm{CaF}_{2}$ crystal studied for comparison which contains predominantly $\mathrm{Tm}^{3+}$ ion clusters. Thus, we assign the absorption lines at $785-805 \mathrm{~nm}$ to another type of sites which fraction decreases when increasing the Tm doping level in the layer (isolated centers). These lines are not found in the excitation spectrum of a bulk 0.05 at.\% $\mathrm{Tm}: \mathrm{CaF}_{2}$ crystal studied for comparison, indicating different assemblage of $\mathrm{Tm}^{3+}$ species in the epitaxial layer. The nature of the isolated $\mathrm{Tm}^{3+}$ centers in epitaxial layers will be further discussed in Section 4.5.

The LT absorption spectra were measured for the $\sim 6$ at. $\% \mathrm{Tm}: \mathrm{CaF}_{2}$ layer and compared with those for a bulk $\mathrm{Tm}: \mathrm{CaF}_{2}$ crystal exhibiting $\mathrm{Tm}^{3+}$ ion clustering. The spectra for $\mathrm{Tm}^{3+}$ ions in the epitaxial layer are smooth and broad at $12 \mathrm{~K}$, indicating significant inhomogeneous broadening. The spectra resemble those for the bulk crystal suggesting the presence of clusters in the $\sim 6$ at. $\%$ Tm-doped layer.

Let us have a closer look at two absorption bands trying to find the signatures of isolated centers. As discussed above, the ${ }^{3} \mathrm{H}_{6} \rightarrow{ }^{3} \mathrm{H}_{4}$ transition in absorption revealed the presence of possible residual isolated centers even at RT. The corresponding extra peak is split at LT resulting in three sharp lines at 791.5, 792.5 and $793.6 \mathrm{~nm}$, Fig. 8(c).

As pointed out above, in bulk $\mathrm{Tm}: \mathrm{CaF}_{2}$ crystals, one of the possible site symmetries for isolated ions is $\mathrm{O}_{\mathrm{h}}$ (cubic). The undistorted $\mathrm{O}_{\mathrm{h}}$ sites are centro-symmetric ones. The presence 
of a center of inversion implies that the ED transitions are forbidden, unless they are vibrationally induced. The MD transitions are however allowed for the $\mathrm{O}_{\mathrm{h}}$ sites. For $\mathrm{Tm}^{3+}$ ions, the transition with a MD contribution is the ${ }^{3} \mathrm{H}_{6} \rightarrow{ }^{3} \mathrm{H}_{5}$ one. The single absorption line corresponding to $\mathrm{O}_{\mathrm{h}}$ sites is easily found in the spectrum of the bulk crystal at $1186.2 \mathrm{~nm}$, Fig. 8(b), in agreement with Refs. [44,45]. It is also preserved in the spectrum of the epitaxial layer. The intense peaks at 1204.2 and $1210.7 \mathrm{~nm}$ which are present in the spectra of both the epitaxial layer and the bulk crystal were assigned by Doroshenko et al. to $\mathrm{Tm}^{3+}$ clusters [45].

\subsection{Judd-Ofelt analysis}

The absorption spectrum of the $\sim 6$ at. $\% \mathrm{Tm}: \mathrm{CaF}_{2}$ film was analyzed using the Judd-Ofelt (J-O) theory $[46,47]$. The $\mathrm{J}-\mathrm{O}$ formalism was applied to ED contributions to transition intensities. The contribution of magnetic-dipole (MD) transitions (for $\Delta \mathrm{J}=\mathrm{J}-\mathrm{J}^{\prime}=0, \pm 1$, except of $\mathbf{J}=\mathbf{J}^{\prime}=0$ ) was calculated separately within the Russell-Saunders approximation on wave functions of $\mathrm{Tm}^{3+}$ under an assumption of a free-ion. The set of squared reduced matrix elements $U^{(k)}$ was calculated using the free-ion parameters from [48]. The dispersion curve of $\mathrm{CaF}_{2}$ reported in [16] was used. The details of the calculation can be found elsewhere [49], here, we only discuss the used approximations.

In the standard J-O theory, the ED line strengths of the $\mathrm{J} \rightarrow \mathrm{J}$ transitions $S^{\mathrm{ED}}\left(\mathrm{JJ}^{\prime}\right)$ are given by $[46,47]$ :

$$
\begin{aligned}
& S_{\text {calc }}^{\mathrm{ED}}\left(J J^{\prime}\right)=\sum_{\mathrm{k}=2,4,6} U^{(\mathrm{k})} \Omega_{\mathrm{k}}, \\
& U^{(\mathrm{k})}=\left\langle\left(4 \mathrm{f}^{\mathrm{n}}\right) S L U\left\|U^{\mathrm{k}}\right\|\left(4 \mathrm{f}^{\mathrm{n}}\right) S^{\prime} L^{\prime} J^{\prime}\right\rangle^{2} .
\end{aligned}
$$

Here, $\mathrm{U}^{(\mathrm{k})}$ are the reduced squared matrix elements and $\Omega_{\mathrm{k}}$ are the intensity $(\mathrm{J}-\mathrm{O})$ parameters $(k=2,4,6)$.

The standard J-O theory can be modified to account for the configuration interaction. If only the lower-energy excited configuration of the opposite parity $\left(4 \mathrm{f}^{\mathrm{n}-1} 5 \mathrm{~d}^{1}\right)$ contributes to the configuration interaction, the ED line strengths are [50,51]:

$$
\begin{aligned}
& S_{\text {calc }}^{\mathrm{ED}}\left(J J^{\prime}\right)=\sum_{\mathrm{k}=2,4,6} U^{(\mathrm{k})} \tilde{\Omega}_{\mathrm{k}}, \\
& \tilde{\Omega}_{\mathrm{k}}=\Omega_{\mathrm{k}}\left[1+2 \alpha\left(E_{\mathrm{J}}+E_{\mathrm{J}^{\prime}}-2 E_{\mathrm{f}}^{0}\right)\right] .
\end{aligned}
$$

Here, the intensity parameters $\tilde{\Omega}_{\mathrm{k}}$ are the linear functions of energies ( $E_{\mathrm{J}}$ and $E_{\mathrm{J}^{\prime}}$ ) of the two multiplets involved in the transition $\mathrm{J} \rightarrow \mathrm{J}^{\prime}, E_{\mathrm{f}}^{0}$ is the mean energy of the $4 \mathrm{f}^{\mathrm{n}}$ configuration and $\alpha \approx 1 /(2 \Delta)$, where $\Delta$ has the meaning of the average energy difference between the $4 \mathrm{f}^{\mathrm{n}}$ and $4 \mathrm{f}^{\mathrm{n}-}$ ${ }^{1} 5 \mathrm{~d}^{1}$ electronic configurations. Thus, there are four free parameters, i.e., $\Omega_{2}, \Omega_{4}, \Omega_{6}$ and $\alpha$. Note that $\widetilde{\Omega}_{\mathrm{k}}$ for the mJ-O theory is transformed into $\Omega_{\mathrm{k}}$ in the standard J-O theory under the assumption of a high-lying $4 \mathrm{f}^{\mathrm{n}-1} 5 \mathrm{~d}^{1}$ excited configuration $(\Delta \rightarrow \infty$ or, equivalently, $\alpha \rightarrow 0)$.

The measured and calculated absorption oscillator strengths (denoted as $f_{\exp }$ and $f_{\text {calc, }}^{\Sigma}$, respectively) are listed in Table 1. Here, the superscript " $\Sigma$ " stands for the total (ED + MD) value. A comparison of the root-mean-square (r.m.s.) deviations between $f_{\exp }$ and $f_{\text {calc }}^{\Sigma}$ indicates that the $\mathrm{mJ}-\mathrm{O}$ theory provides a much better agreement between the experimental and calculated values. Indeed, the r.m.s. deviation equals to $0.880(\mathrm{~J}-\mathrm{O})$ and 0.369 (mJ-O). 
Note that during the calculations, the ${ }^{3} \mathrm{H}_{6} \rightarrow{ }^{3} \mathrm{~F}_{4}$ transition in absorption was excluded to avoid underestimating the radiative lifetime of the ${ }^{3} \mathrm{~F}_{4}$ state. In our recent study [52], we showed that due to the strong spin-orbit interaction, $\mathrm{Tm}^{3+}$ multiplets with the same total angular momentum quantum number $\mathrm{J}=4$ (i.e., ${ }^{3} \mathrm{~F}_{4},{ }^{3} \mathrm{H}_{4}$ and ${ }^{1} \mathrm{G}_{4}$ ) in certain matrices can form a group of strongly interconnected states. Thus, through the ${ }^{1} \mathrm{G}_{4}$ excited-state of the $4 \mathrm{f}^{\mathrm{n}}$ configuration, the effect of excited configurations (e.g., $4 \mathrm{f}^{\mathrm{n}-1} 5 \mathrm{~d}^{1}$ ) is transferred to the lower-lying states.

The obtained intensity parameters are listed in Table 2 . For the mJ-O theory, they are $\Omega_{2}$ $=3.833, \Omega_{4}=1.449$ and $\Omega_{6}=2.569\left[10^{-20} \mathrm{~cm}^{2}\right]$ and $\alpha=0.269\left[10^{-4} \mathrm{~cm}\right]$, so that the phenomenological parameter $\Delta=1.86 \times 10^{4} \mathrm{~cm}^{-1}$.

The probabilities of radiative spontaneous transitions for individual emission channels

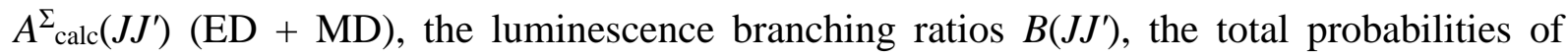
spontaneous radiative transitions from the excited states $A_{\text {tot }}$ and the corresponding radiative lifetimes $\tau_{\text {rad }}$ are listed in Table 3. They are obtained using the mJ-O theory. For the ${ }^{3} \mathrm{~F}_{4}$ and ${ }^{3} \mathrm{H}_{4}$ $\mathrm{Tm}^{3+}$ multiplets, $\tau_{\mathrm{rad}}$ is $21.30 \mathrm{~ms}$ and $1.11 \mathrm{~ms}$, respectively.

\subsection{Luminescence spectra}

The spectra of RT near-IR luminescence from the Tm:CaF 2 epitaxial layers are shown in Fig. 9(a) ( $\lambda_{\text {exc }}=768 \mathrm{~nm}$, excitation to the ${ }^{3} \mathrm{H}_{4}$ state). For the highly-doped ( 6 at. $\% \mathrm{Tm}$ ) layer, an emission band with a maximum at $\sim 1830 \mathrm{~nm}$ is observed and assigned to the ${ }^{3} \mathrm{~F}_{4} \rightarrow{ }^{3} \mathrm{H}_{6}$ transition of $\mathrm{Tm}^{3+}$ ions forming clusters. It is smooth and broad (a "glassy"-like behavior), except for two local peaks in the short-wavelength part (at 1613 and $1667 \mathrm{~nm}$ ). The emission bandwidth (FWHM) $\Delta \lambda_{\text {lum is }} 182 \mathrm{~nm}$. The shape of this band greatly resembles that for a highlydoped bulk Tm:CaF2 crystal, Fig. 9 (a), but it is broader (for the bulk crystal, $\Delta \lambda_{\text {lum }}=144 \mathrm{~nm}$ ) which implies more complex assemblage of $\mathrm{Tm}^{3+}$ species.

For the $\sim 2$ at.\% Tm-doped film, the emission spectrum is very different. First, the ${ }^{3} \mathrm{~F}_{4} \rightarrow$ ${ }^{3} \mathrm{H}_{6}$ band is strongly structured exhibiting several prominent peaks at $1700,1721,1744,1768$, 1822,1862 (the most intense) and $1891 \mathrm{~nm}$. Second, another emission band with a maximum at $\sim 1420 \mathrm{~nm}$ which also contains a set of well-resolved peaks appears, see Fig. 9(b). It is related to the ${ }^{3} \mathrm{H}_{4} \rightarrow{ }^{3} \mathrm{~F}_{4} \mathrm{Tm}^{3+}$ transition and in the case of $\mathrm{Tm}: \mathrm{CaF}_{2}$, it indicates the presence of isolated ions. In $\mathrm{Tm}^{3+}$-doped materials, there exist an efficient cross-relaxation (CR) process between adjacent $\mathrm{Tm}^{3+}$ ions, ${ }^{3} \mathrm{H}_{4}\left(\mathrm{Tm}_{1}\right)+{ }^{3} \mathrm{H}_{6}\left(\mathrm{Tm}_{2}\right) \rightarrow{ }^{3} \mathrm{~F}_{4}\left(\mathrm{Tm}_{1}\right)+{ }^{3} \mathrm{~F}_{4}\left(\mathrm{Tm}_{2}\right)$, which depopulates the ${ }^{3} \mathrm{H}_{4}$ state and greatly reduces its luminescence lifetime. Obviously, CR is greatly promoted for $\mathrm{Tm}^{3+}$ ions within clusters, so that the emissions from the ${ }^{3} \mathrm{H}_{4}$ state are very weak even at low $\mathrm{Tm}$ doping levels (>0.1 at.\%) in bulk $\mathrm{CaF}_{2}$ crystals [17]. Indeed, the study of a $\sim 1.5$ at.\% Tm:CaF 2 bulk crystal, Fig. 7(a), reveals no signs of the ${ }^{3} \mathrm{H}_{4} \rightarrow{ }^{3} \mathrm{~F}_{4}$ emission. It is observed only for the 0.05 at. $\%$ Tm-doped bulk crystal. Thus, for the $\sim 2$ at.\% Tm-doped layer, a significant amount of ions remains isolated. The shapes of the ${ }^{3} \mathrm{H}_{4} \rightarrow{ }^{3} \mathrm{~F}_{4}$ emission bands for the epitaxial layer and the bulk crystal are rather different suggesting the presence of isolated $\mathrm{Tm}^{3+}$ species of different nature in agreement with Section 4.3.

To reveal the nature of $\mathrm{Tm}^{3+}$ centers in the epitaxial layers with different doping levels, first, LT luminescence spectra corresponding to the ${ }^{3} \mathrm{~F}_{4} \rightarrow{ }^{3} \mathrm{H}_{6} \mathrm{Tm}^{3+}$ transition were measured 
under spectrally-selective excitation, see Fig. 10. In the same figure, for comparison, we have also provided the spectra for bulk 0.05 at.\% Tm: and 4.5 at.\% $\mathrm{Tm}: \mathrm{CaF}_{2}$ crystals.

For $\sim 2$ at.\% Tm-doped layer, by scanning the excitation wavelength around $790 \mathrm{~nm}$ (the spectral range corresponding to absorption lines of non-identified centers, see Section 4.3), two distinct types of emission spectra were observed, Fig. 10(a), corresponding to $\lambda_{\mathrm{exc}}=792.5$ and $793.6 \mathrm{~nm}$. None of them can be assigned to $\mathrm{C}_{3 \mathrm{v}}$ and $\mathrm{C}_{4 \mathrm{v}}$ sites, as evidenced by the measurement performed for the bulk 0.05 at.\% Tm:CaF2 crystal, Fig. 10(b). In Fig. 10(a,b), to simplify the assignment, using known crystal-field splitting of the ${ }^{3} \mathrm{H}_{4}$ and ${ }^{3} \mathrm{~F}_{4}$ multiplets of $\mathrm{Tm}^{3+}$ in the trigonal and tetragonal sites [53,54] and considering the symmetry selection rules [55], we have also calculated the wavelengths of electronic transitions shown by vertical dashes. Thus, we searched for other possible isolated centers. It is known that for $\mathrm{CaF}_{2}$ crystals, the local charge compensation can be also achieved by oxygen resulting in trigonal oxygen-assisted sites $\mathrm{C}_{3 \mathrm{v}}\left(\mathrm{T}_{2}\right)$ [56] appearing instead of the fluorine-compensated $\mathrm{C}_{3 \mathrm{v}}$ ones. The emission spectrum of the $\sim 2$ at.\% Tm-doped layer observed for $\lambda_{\mathrm{exc}}=793.6 \mathrm{~nm}$ is well explained assuming the presence of $\mathrm{C}_{3 \mathrm{v}}\left(\mathrm{T}_{2}\right)$ sites.

For the $\sim 6$ at.\% Tm-doped layer, cf. Fig. 10(c), the LT luminescence spectrum exhibits broad and smooth bands and it is barely sensitive to the excitation wavelength, as shown for the example of $\lambda_{\text {exc }}=762.7 \mathrm{~nm}$. The spectrum also greatly resembles that for the bulk 4.5 at. $\%$ Tm: $\mathrm{CaF}_{2}$ crystal, Fig. 10(d). This type of emission is thus assigned to $\mathrm{Tm}^{3+}$ clusters. By tuning the excitation wavelength to $\lambda_{\mathrm{exc}}=793.6 \mathrm{~nm}$, weak signatures of isolated $\mathrm{C}_{3 \mathrm{v}}\left(\mathrm{T}_{2}\right)$ sites were detected.

As pointed out above, the ${ }^{3} \mathrm{H}_{4} \rightarrow{ }^{3} \mathrm{~F}_{4}$ luminescence is very sensitive to the nature of $\mathrm{Tm}^{3+}$ emitting centers (i.e., isolated ions or clusters). Thus, it was also studied at low temperature, Fig. 11. No luminescence owing to this transition was observed for the $\sim 6$ at. $\%$ Tm-doped layer, as expected. For the $\sim 2$ at. $\%$ Tm-doped layer, $\lambda_{\mathrm{exc}}=793.6 \mathrm{~nm}$ leads to intense emission with distinct peaks well explained by electronic transitions of $\mathrm{Tm}^{3+}$ ions located in the $\mathrm{C}_{3 \mathrm{v}}\left(\mathrm{T}_{2}\right)$ sites (with the wavelengths calculated from the known crystal-field splitting [54] and marked by red dashes), Fig. 11(a). In contrast, for $\lambda_{\mathrm{exc}}=792.5 \mathrm{~nm}$, no emission was observed. The latter suggests that the corresponding centers are not isolated and probably represent small clusters (e.g., dimers) which are different from those observed in the $\sim 6$ at. $\%$ Tm-doped layer. However, it is difficult to argue if the charge compensation in such small clusters is provided by oxygen or fluorine. No spectroscopic signatures of $\mathrm{C}_{3 \mathrm{v}}$ and $\mathrm{C}_{4 \mathrm{v}}$ sites are found for the $\sim 2$ at.\% Tm:CaF 2 layer, while both of them are easily found for the bulk 0.05 at.\% Tm:CaF 2 crystal, Fig. 11(b).

\subsection{Luminescence decay}

The RT luminescence decay curves for the Tm: $\mathrm{CaF}_{2}$ epitaxial layers are shown in Fig. 12 corresponding to emissions from the ${ }^{3} \mathrm{~F}_{4}$ and ${ }^{3} \mathrm{H}_{4}$ states. In the first experiments with the asgrown films, we observed a "fast" component (characteristic decay time: $<100 \mu \mathrm{s}$ ) in the decay curves from the ${ }^{3} \mathrm{~F}_{4}$ state, as shown by the grey curve in Fig. 12(a). However, it was completely eliminated by polishing the top-surface of the films and removing the residual solvent (LiF) and imperfect part of the film. We believe that the "fast" component may represent the effect of defect-assisted sites located near the film surface, small Tm:CaF 2 crystallites formed during the 
film cooling, or energy-transfer to defect states in LiF. For the polished $\sim 6$ at. $\%$ Tm-doped film, the decay from the ${ }^{3} \mathrm{~F}_{4}$ state is well fitted using a single-exponential law yielding the lifetime $\tau_{\text {lum }}=21.70 \mathrm{~ms}$ which is assigned to $\mathrm{Tm}^{3+}$ clusters .

The lifetime measurements in $\mathrm{Tm}^{3+}$-doped materials may be affected by reabsorption. To confirm the correctness of our studies, we applied the pinhole method [57] for the $\sim 6$ at.\% Tmdoped film and did not detect any noticeable variation of $\tau_{\text {lum }}$ with the pinhole diameter. This can be understood considering the very small thickness of the studied film $(t \sim 10 \mu \mathrm{m})$.

The luminescence decay from the ${ }^{3} \mathrm{~F}_{4}$ state for the $\sim 2$ at.\% Tm-doped film is clearly nonsingle-exponential. When applying a bi-exponential fit, we achieve $\tau$ lum $1=4.8 \pm 0.5 \mathrm{~ms}$ and $\tau$ lum 2 $=24.9 \pm 0.7 \mathrm{~ms}$. This observation agrees with our assumption of the multi-site nature of this sample. According to the previous spectrally-selective lifetime measurements performed for bulk Tm: $\mathrm{CaF}_{2}$ crystals [54], we assign the $\tau_{\text {lum } 1}$ and $\tau_{\text {lum2 }}$ lifetimes to $\mathrm{C}_{3 \mathrm{v}}\left(\mathrm{T}_{2}\right)$ and cluster sites, respectively.

The ${ }^{3} \mathrm{~F}_{4}$ lifetimes determined in the present study are longer than those measured for the $\sim 1$ at.\% Tm: $\mathrm{CaF}_{2}$ epitaxial film grown using the $\mathrm{CaCl}_{2}$ solvent ( $\tau$ lum $=12.8 \mathrm{~ms}$, singleexponential fit) [31]. In [31], the lifetime reduction was assigned to quenching effects possibly related to defects and impurities.

As pointed out above, the emissions from the ${ }^{3} \mathrm{H}_{4} \mathrm{Tm}^{3+}$ state in $\mathrm{CaF}_{2}$ are very sensitive to ion clustering due to cross-relaxation. The decay curves from the ${ }^{3} \mathrm{H}_{4}$ state for the epitaxial $\mathrm{Tm}: \mathrm{CaF}_{2}$ films are shown in Fig. 12(b) and their shape is characteristic for systems with $\mathrm{CR}$ $[58,59]$. The initial part of the decay curve represents the energy-transfer and the "slow" part which is well fitted with a single-exponential law corresponds to the intrinsic lifetime of the ${ }^{3} \mathrm{H}_{4}$ state. For the $\sim 2$ at.\% Tm-doped epitaxy, the intrinsic lifetime $\tau$ lum $0=1.26 \pm 0.1 \mathrm{~ms}$ and the average one $\left\langle\tau_{\text {lum }}\right\rangle=0.90 \mathrm{~ms}$. For the $\sim 6$ at. $\%$ Tm-doped film, both values are shorter, namely $\tau_{\text {lum } 0}=0.87 \pm 0.05 \mathrm{~ms}$ (which is probably due to enhanced energy-migration to defects and impurities) and $\left\langle\tau_{\text {lum }}\right\rangle=0.175 \mathrm{~ms}$ (which is also indicative of enhanced CR). Note that the use of rate-equation formalism for the analysis of decay curves from the ${ }^{3} \mathrm{H}_{4}$ state as in the previous work [59] is complicated in our case due to the presence of several types of emitting centers (isolated ions and clusters) with their relative ratios being unknown.

\subsection{Stimulated-emission cross-sections}

The stimulated-emission (SE) cross-sections, $\sigma$ SE, for the ${ }^{3} \mathrm{~F}_{4} \rightarrow{ }^{3} \mathrm{H}_{6}$ transition of $\mathrm{Tm}^{3+}$ ions in highly-doped film were calculated using the Füchtbauer-Ladenburg (F-L) equation [60]:

$$
\sigma_{\mathrm{SE}}(\lambda)=\frac{\lambda^{5}}{8 \pi n^{2} \tau_{\mathrm{rad}} c} \frac{W(\lambda)}{\int \lambda W(\lambda) \mathrm{d} \lambda},
$$

where, $W(\lambda)$ is the luminescence spectrum calibrated for the spectral response of the set-up, $\lambda$ is the light wavelength, $n$ is the refractive index at the mean emission wavelength [16], $c$ is the speed of light, $\tau_{\text {rad }}$ is the radiative lifetime of the emitting state $\left({ }^{3} \mathrm{~F}_{4}\right)$. The results on $\sigma$ SE for the $\sim 6$ at.\% Tm-doped layer are shown in Fig. 13(a) and compared with those for a highly-doped bulk crystal. For the epitaxial layer, the maximum $\sigma \mathrm{SE}=0.14 \times 10^{-20} \mathrm{~cm}^{2}$ at $1856 \mathrm{~nm}$ and it is lower than for the corresponding bulk crystal $\left(0.23 \times 10^{-20} \mathrm{~cm}^{2}\right.$ at $\left.1850 \mathrm{~nm}\right)$. Here, the difference originates mainly from the lifetimes used for the calculation. Physically, the broadening of the 
emission band and the reduction of the peak SE cross-sections is due to the more complex assemblage of $\mathrm{Tm}^{3+}$ species in the epitaxial layer (e.g., probably slightly different geometry of clusters).

The ${ }^{3} \mathrm{~F}_{4} \rightarrow{ }^{3} \mathrm{H}_{6} \mathrm{Tm}^{3+}$ transition represents a quasi-three level scheme with reabsorption. Thus, the gain cross-sections, $\sigma_{\mathrm{g}}=\beta \sigma \mathrm{SE}-(1-\beta) \sigma_{\mathrm{abs}}$, where $\beta=N_{2}\left({ }^{3} \mathrm{~F}_{4}\right) / N_{\mathrm{Tm}}$ is the inversion ratio and $N_{2}$ is the population of the upper multiplet, were calculated, Fig. 13(b). The gain spectra are smooth and broad. For small $\beta=0.10$, the local maximum in the gain spectrum is located at $\sim 1.94 \mu \mathrm{m}$. With increasing the inversion ratio, the gain spectrum experiences a blueshift reaching $\sim 1.86 \mu \mathrm{m}$ for high $\beta=0.40$. The determined gain spectra emphasize the advantage of using highly-doped $\mathrm{Tm}: \mathrm{CaF}_{2}$ films for broadband amplification and ultrashort pulse generation in waveguide geometry.

\subsection{Isolated ions: discussion}

Oxygen-assisted sites. In our previous study of 1.4 at.\% $\mathrm{Yb}: \mathrm{CaF}_{2}$ epitaxial layers grown using another solvent $\left(\mathrm{CaCl}_{2}\right)$, it was evidenced that a significant fraction of $\mathrm{Yb}^{3+}$ ions is located in isolated sites [22]. The assemblage of $\mathrm{Yb}^{3+}$ species was as following: isolated sites $\left(\mathrm{C}_{3 \mathrm{v}}\left(\mathrm{T}_{2}\right)\right.$ - predominantly, $\mathrm{O}_{\mathrm{h}}$ - well-detected and $\mathrm{C}_{4 \mathrm{v}}$ - minor fraction) and clusters. This agrees with the present work.

We relate the presence of oxygen in the films to the possible weak pollution of the molten bath with residual moisture and / or oxygen traces in the growth chamber, despite a special attention was paid to reach a good secondary vacuum before starting the molten ramp of the precursors. Fluorides in the molten state are very sensitive to oxygen pollution. For the technical point of view, we cannot exclude the infiltration of air through the seals of the pulling cane by dint of repeated translations or due to many openings of the exchange airlock to change and install samples at the extremity of the cane, despite the systematic pumping and Ar-refilling of the charging dock. The LPE run is typically done during few weeks comprising multiple samples.

Cubic sites. The presence of cubic sites in even highly-doped $\mathrm{Tm}: \mathrm{CaF}_{2}$ films is not surprising. Petit et al. indicated that in bulk $\mathrm{Yb}: \mathrm{CaF}_{2}$ crystals, the relative fraction of isolated ions residing in $\mathrm{O}_{\mathrm{h}}$ sites is barely sensitive to the doping concentration (in the range of 0.03 0.12 at.\%) as compared to those for the $\mathrm{C}_{3 \mathrm{v}}$ and $\mathrm{C}_{4 \mathrm{v}}$ sites whose relative occupations decrease at the expense of cluster formation [42]. A similar conclusion was made in [61] for bulk $\mathrm{CaF}_{2}$ doped with 0.01-0.2 mol\% Er.

It is also known that univalent alkali metals $\left(\mathrm{Na}^{+}, \mathrm{Li}^{+}, \mathrm{K}^{+}\right)$may enter into the $\mathrm{CaF}_{2}$ lattice [62]. They can be intentionally introduced in the form of the $\mathrm{NaF}, \mathrm{LiF}$ or KF reagents [63] or may come as impurities. The sites formed by the $\mathrm{Tm}^{3+}$ and $\mathrm{Na}^{+}$cations exhibit $\mathrm{C}_{2 \mathrm{v}}$ symmetry. In addition, $\mathrm{Tm}^{3+}$ ions in $\mathrm{Na}$-codoped $\mathrm{CaF}_{2}$ crystals can reside in cubic sites $\left(\mathrm{O}_{\mathrm{h}}\right)$ with a nonlocal charge compensation, however, the symmetry of these cubic sites is disturbed by neighboring $\mathrm{Na}^{+}$cations. It was found that the alkali metal codoping of $\mathrm{CaF}_{2}$ promotes the formation of cubic sites for rare-earth dopants [62].

In analogy to $\mathrm{Na}^{+}$codoping of $\mathrm{Tm}: \mathrm{CaF}_{2}$, one may suggest the presence of $\mathrm{Li}^{+}$in the grown films. Bulk Tm,Li:CaF 2 crystals were grown [62]. However, due to a large difference of ionic 
radii of $\mathrm{Ca}^{2+}$ and $\mathrm{Li}^{+}$(as compared to $\mathrm{Na}^{+}$), the segregation of $\mathrm{Li}^{+}$in $\mathrm{CaF}_{2}$ is very low. Nevertheless, we cannot exclude that a certain (small) amount of $\mathrm{Li}$ is present in our films, especially since LiF has been used as a solvent. The EDX analysis did not allow to detect lithium due to its too low atomic number.

Isolated ions vs. clusters. To summarize, our studies indicate that with the Tm doping of epitaxial $\mathrm{CaF}_{2}$ films, the probability of cluster formation increases, but this tendency is much slower than in in the case of bulk crystals. As a result, a significant fraction of isolated ions is present in $\sim 2$ at.\% Tm-doped films and isolated ions are still found in $\sim 6$ at. $\%$ Tm-doped films. The site symmetries for the isolated ions are identified as $\mathrm{C}_{3 \mathrm{v}}\left(\mathrm{T}_{2}\right)$ and $\mathrm{O}_{\mathrm{h}}$.

A similar tendency for "slow" clustering was observed previously in rare-earth doped $\mathrm{CaF}_{2}$ films grown by MBE. Daran et al. studied films doped with $\mathrm{Er}$ and indicated that the relative fraction of ions in $\mathrm{C}_{4 \mathrm{v}}$ sites with respect to those forming clusters decreases rapidly with the doping level; almost no isolated ions were found at $\sim 6 \mathrm{~mol} \% \mathrm{Er}$ doping [64]. The authors pointed out that this process is slowed down as compared to bulk crystals for which a similar effect already occurred at $\sim 1 \mathrm{~mol} \%$ Er [64]. Bausa et al. studied Nd-doped $\mathrm{CaF}_{2}$ films and concluded that the lower growth temperature in the case of MBE greatly affects the formation of clusters involving several $\mathrm{Nd}^{3+}$ - F- pairs [65]. This was assigned to solid-state diffusion which is slowed down with reducing the temperature: Osiko et al. indicated that the impurity complexes become virtually immobile at the temperatures below $600{ }^{\circ} \mathrm{C}$ [66]. Moreover, it was stated that for a given doping concentration, the distribution of ions over different types of sites (both isolated or clusters) is different for epitaxial films and bulk crystals [65]. This agrees with our observations.

The authors of [67] indicated that the assemblage of rare-earth species in $\mathrm{CaF}_{2}$ depends on the thermodynamic equilibrium conditions during the growth of the films or bulk crystals. Drazic et al. indicated that the degree of inhomogeneous distribution of $\mathrm{Tm}^{3+}$ ions in bulk $\mathrm{CaF}_{2}$ and ion clustering depend on (i) the heat flow gradients across the interface between the melt and solid phases, (ii) the temperature gradient in the crucible and (iii) the spatial correlation between the density fluctuations in the liquid phase. The growth temperatures for the studied LPE films $T=815-856{ }^{\circ} \mathrm{C}$ are significantly lower than the growth temperature of bulk $\mathrm{Tm}: \mathrm{CaF}_{2}$ which lies around $1418{ }^{\circ} \mathrm{C}$. The vertical thermal gradients in the crucible during the LPE growth were estimated as $0.5-1{ }^{\circ} \mathrm{C} / \mathrm{cm}$, whereas they are about $\sim 40{ }^{\circ} \mathrm{C} / \mathrm{cm}$ in the case of bulk $\mathrm{CaF}_{2}$ crystals grown by the Bridgman technique. The different thermodynamic conditions during the LPE growth and the bulk crystal growth and, in particular, much lower growth temperature in the former case, can also explain the notable difference of segregation coefficients of rare-earth ions in these two forms of $\mathrm{CaF}_{2}\left(K_{\mathrm{Tm}}\right.$ is near unity for bulk crystals and almost twice smaller for LPE films).

\subsection{Waveguiding properties}

It is known that rare-earth doping of $\mathrm{CaF}_{2}$ enhances its refractive index. Thus, Tm: $\mathrm{CaF}_{2} /$ $\mathrm{CaF}_{2}$ epitaxies can serve as optical waveguides (in planar geometry). To verify this, we studied a $\sim 2$ at.\% Tm-doped epitaxy. Its top surface was polished to laser quality resulting in a film thickness of $36 \pm 1 \mu \mathrm{m}$. The input and output facets were also polished with good parallelism 
and the length of the sample was $5.0 \mathrm{~mm}$. Figure 14 shows the near-field profile of the guided mode at $770 \mathrm{~nm}$ at the output facet of the epitaxy. The mode has a characteristic horizontal stripe profile typical for planar waveguides. The variation of the refractive index in the $\sim 2$ at. $\%$ Tm-doped epitaxy, $\Delta n=n_{\text {layer }}-n_{\text {substrate, }}$ was estimated to be $0.008\left(n_{\text {substrate }}=1.432\right)$ at the wavelength of $632.8 \mathrm{~nm}$, using the data from [31].

A rough upper estimation for waveguide propagation losses was obtained from the pumptransmission measurements at $\sim 850 \mathrm{~nm}$ (out of $\mathrm{Tm}^{3+}$ absorption), $\delta$ loss $<1 \mathrm{~dB} / \mathrm{cm}$. The precision was limited by the relatively short epitaxial sample. In [22] for a similar 1.4 at.\% Yb:CaF2 epitaxy, $\delta$ loss was estimated with higher precision from the Findlay-Clay analysis of the laser performance to be as low as $0.14 \pm 0.05 \mathrm{~dB} / \mathrm{cm}$ at $\sim 1 \mu \mathrm{m}$.

\section{Conclusions}

The spectroscopic study of $\mathrm{Tm}^{3+}$-doped $\mathrm{CaF}_{2}$ layers grown by LPE allowed us to draw the following conclusions:

(i) The predominant type of sites for isolated $\mathrm{Tm}^{3+}$ ions in the epitaxial films is the oxygen-assisted trigonal site $\mathrm{C}_{3 \mathrm{v}}\left(\mathrm{T}_{2}\right)$. No spectroscopic signatures of fluorine-compensated $\mathrm{C}_{3 \mathrm{v}}$ and $\mathrm{C}_{4 \mathrm{v}}$ sites are found in the films doped with $\sim 2$ at. $\% \mathrm{Tm}$ while a certain fraction of ions reside in cubic sites $\left(\mathrm{O}_{\mathrm{h}}\right)$ which are preserved even at high doping levels ( $\sim 6$ at.\% $\mathrm{Tm}$ ).

(ii) With increasing the doping level, $\mathrm{Tm}^{3+}$ ions tend to form clusters with optical properties similar to those in bulk Tm: $\mathrm{CaF}_{2}$ crystals. Highly-doped Tm: $\mathrm{CaF}_{2}$ films contain predominantly clusters leading to smooth and broad spectral bands (a "glassy-like" behavior) and a nearly single-exponential decay from the upper laser level $\left({ }^{3} \mathrm{~F}_{4}\right)$ with a lifetime of 21.70 ms which is well explained by the Judd-Ofelt theory.

(iii) The formation of Tm clusters in the epitaxial films with their doping is slowed down as compared to the corresponding single crystals. This is explained by the different thermodynamic growth conditions for the epitaxial layers and bulk crystals, and, in particular, by much lower growth temperature for the LPE method $\left(T=815-856^{\circ} \mathrm{C}\right.$, in the present work) slowing down the solid-state diffusion of defects serving for charge compensation (e.g., interstitial fluorine, $\mathrm{F}_{\mathrm{i}}^{-}$and / or oxygen $\mathrm{O}^{2-}$ ). As a result, a significant part of $\mathrm{Tm}^{3+}$ ions in $\sim 2$ at.\% Tm-doped films is located in isolated sites which has a direct consequence on the emission properties. Even for $\sim 6$ at. $\%$ Tm-doped films, the spectroscopic signatures of ions in $\mathrm{C}_{3 \mathrm{v}}\left(\mathrm{T}_{2}\right)$ and $\mathrm{O}_{\mathrm{h}}$ sites can still be found.

The detailed morphological study of the films allowed us to conclude that $\mathrm{Tm}^{3+}$-doped $\mathrm{CaF}_{2}$ layers grown on (100) oriented substrates are prone to crazing forming a characteristic rectangular pattern of cracks oriented along the [011] and [011 ${ }^{-}$] directions. This effect seems to be promoted by Tm doping. It can be greatly reduced by a proper temperature regime of the epitaxial growth. One may argue that such micro-cracks or even dislocations that are not directly visible as cracks increase the waveguide propagation losses of the films, so that the elimination of crazing is crucial. As pointed out above, it can be reached by a proper (e.g., twostep) temperature regime or by using other substrate orientations, e.g., (111) or non-oriented ones. 
Highly-doped Tm:CaF2 films with predominantly clustered $\mathrm{Tm}^{3+}$ ions, because of their smooth and broad emission spectra of the ${ }^{3} \mathrm{~F}_{4} \rightarrow{ }^{3} \mathrm{H}_{6}$ transition, efficient cross-relaxation between adjacent $\mathrm{Tm}^{3+}$ ions and long upper laser lifetime are promising for waveguide laser applications at $\sim 2 \mu \mathrm{m}$.

\section{Acknowledgements}

This work was supported by French Agence Nationale de la Recherche (ANR) through the projects LabEx EMC3 (ANR-10-LABX-09-01), SPLENDID2 (ANR-19-CE08-0028), and the European project "NOVAMAT" co-funded by the European Community funds FEDER and the Normandie region.

\section{References}

1. P. Camy, J.L. Doualan, S. Renard, A. Braud, V. Menard, R. Moncorgé, $\mathrm{Tm}^{3+}: \mathrm{CaF}_{2}$ for $1.9 \mu \mathrm{m}$ laser operation, Opt. Commun. 236 (2004) 395-402.

2. R. C. Stoneman, L. Esterowitz, Efficient, broadly tunable, laser-pumped Tm:YAG and Tm:YSGG cw lasers, Opt. Lett. 15 (1990) 486-488.

3. Y. Wang, W. Chen, M. Mero, L. Zhang, H. Lin, Z. Lin, G. Zhang, F. Rotermund, Y. J. Cho, P. Loiko, X. Mateos, U. Griebner, V. Petrov, Sub-100 fs Tm:MgWO 4 laser at 2017 nm mode locked by a graphene saturable absorber, Opt. Lett. 42 (2017) 3076-3079.

4. M. Schellhorn, High-power diode-pumped Tm: YLF laser, Appl. Phys. B 91 (2008) 71-74.

5. K. van Dalfsen, S. Aravazhi, C. Grivas, S. M. García-Blanco, M. Pollnau, Thulium channel waveguide laser with $1.6 \mathrm{~W}$ of output power and $~ 80 \%$ slope efficiency, Opt. Lett. 39 (2014) 43804383.

6. A. Rameix, C. Borel, B. Chambaz, B. Ferrand, D. P. Shepherd, T. J. Warburton, D. C. Hanna, A. C. Tropper, An efficient, diode-pumped, $2 \mu \mathrm{m}$ Tm:YAG waveguide laser, Opt. Commun. 142 (1997) 239-243.

7. W. Bolanos, F. Starecki, A. Benayad, G. Brasse, V. Ménard, J.-L. Doualan, A. Braud, R. Moncorgé, P. Camy, Tm:LiYF 4 planar waveguide laser at $1.9 \mu \mathrm{m}$, Opt. Lett. 37 (2012) 4032-4034.

8. W. Bolaños, J. J. Carvajal, X. Mateos, E. Cantelar, G. Lifante, U. Griebner, V. Petrov, V. L. Panyutin, G. S. Murugan, J. S. Wilkinson, M. Aguiló, F. Díaz, Continuous-wave and Q-switched Tmdoped $\mathrm{KY}\left(\mathrm{WO}_{4}\right)_{2}$ planar waveguide laser at $1.84 \mu \mathrm{m}$, Opt. Express 19 (2011) 1449-1454.

9. K. van Dalfsen, S. Aravazhi, D. Geskus, K. Wörhoff, M. Pollnau, Efficient KY 1-x${ }_{\mathrm{y}} \mathrm{Gd}_{\mathrm{x}} \mathrm{Lu}_{\mathrm{y}}\left(\mathrm{WO}_{4}\right)_{2}: \mathrm{Tm}^{3+}$ channel waveguide lasers, Opt. Express 19 (2011) 5277-5282.

10. P. Loiko, R. Soulard, G. Brasse, J.-L. Doualan, B. Guichardaz, A. Braud, A. Tyazhev, A. Hideur, P. Camy, Watt-level Tm:LiYF 4 channel waveguide laser produced by diamond saw dicing, Opt. Express 26 (2018) 24653-24662.

11. P. Loiko, J. M. Serres, X. Mateos, S. Tacchini, M. Tonelli, S. Veronesi, D. Parisi, A. Di Lieto, K. Yumashev, U. Griebner, V. Petrov, Comparative spectroscopic and thermo-optic study of Tm:LiLnF 4 $(\mathrm{Ln}=\mathrm{Y}, \mathrm{Gd}$, and $\mathrm{Lu}$ ) crystals for highly-efficient microchip lasers at $\sim 2 \mu \mathrm{m}$, Opt. Mater. Express 7 (2017) 844-854.

12. M. Chen, P. Loiko, J. M. Serres, S. Veronesi, M. Tonelli, M. Aguiló, F. Díaz, J. E. Bae, T. G. Park, F. Rotermund, S. Dai, Z. Chen, U. Griebner, V. Petrov, X. Mateos, Fluorite-type $\mathrm{Tm}^{3+}: \mathrm{KY}_{3} \mathrm{~F}_{10}$ : A promising crystal for watt-level lasers at $\sim 1.9 \mu \mathrm{m}$, J. Alloys Compd. 813 (2020) 152176-1-8.

13. F. Cornacchia, D. Parisi, C. Bernardini, A. Toncelli, M. Tonelli, Efficient, diode-pumped $\mathrm{Tm}^{3+}: \mathrm{BaY}_{2} \mathrm{~F}_{8}$ vibronic laser, Opt. Express 12 (2004) 1982-1989. 
14. A. Sottile, E. Damiano, M. Rabe, R. Bertram, D. Klimm, M. Tonelli, Widely tunable, efficient 2 $\mu \mathrm{m}$ laser in monocrystalline $\mathrm{Tm}^{3+}: \mathrm{SrF}_{2}$, Opt. Express 26 (2018) 5368-5380.

15. G. A. Slack, Thermal conductivity of $\mathrm{CaF}_{2}, \mathrm{MnF}_{2}, \mathrm{CoF}_{2}$, and $\mathrm{ZnF}_{2}$ crystals, Phys. Rev. 122 (1961) 1451.

16. I. H. Malitson, A redetermination of some optical properties of calcium fluoride, Appl. Opt. 2 (1963) 1103-1107.

17. S. Renard, P. Camy, A. Braud, J.L. Doualan, R. Moncorgé, $\mathrm{CaF}_{2}$ doped with $\mathrm{Tm}^{3+}$ : A cluster model, J. Alloys Compd 451 (2008) 71-73.

18. J. Liu, C. Zhang, Z. Zhang, J. Wang, X. Fan, J. Liu, L. Su, 1886-nm mode-locked and wavelength tunable Tm-doped $\mathrm{CaF}_{2}$ lasers, Opt. Lett. 44, 134-137 (2019).

19. Z. Zhang, X. Guo, J. Wang, C. Zhang, J. Liu, L. Su, High-efficiency $2 \mu$ m continuous-wave laser in laser diode-pumped $\mathrm{Tm}^{3+}, \mathrm{La}^{3+}: \mathrm{CaF}_{2}$ single crystal, Opt. Lett. 43 (2018) 4300-4303.

20. K. Nassau, Application of the Czochralski method to divalent metal fluorides, J. Appl. Phys. 32 (1961) 1820-1821.

21. L.E. Bausa, G. Lifante, E. Daran, P.L. Pernas, $\mathrm{CaF}_{2}: \mathrm{Er}^{3+}$ molecular beam epitaxial layers as optical waveguides, Appl. Phys. Lett. 68 (1996), 3242-3244.

22. P. Loiko, R. Soulard, E. Kifle, L. Guillemot, G. Brasse, A. Benayad, J.-L. Doualan, A. Braud, M. Aguiló, F. Díaz, X. Mateos, P. Camy, Ytterbium calcium fluoride waveguide laser, Opt. Express 27 (2019) 12647-12658.

23. L.J. Schowalter, R.W. Fathauer, R.P. Goehner, L.G. Turner, R.W. DeBlois, S. Hashimoto, J.L. Peng, W.M. Gibson, J.P. Krusius, Epitaxial growth and characterization of $\mathrm{CaF}_{2}$ on Si, J. Appl. Phys. 58 (1985) 302-308.

24. R.W. Fathauer, L.J. Schowalter, Surface morphology of epitaxial $\mathrm{CaF}_{2}$ films on Si substrates, Appl. Phys. Lett. 45 (1984) 519-521.

25. S. Sinharoy, R.A. Hoffman, J.H. Rieger, R.F.C. Farrow, A.J. Noreika, Epitaxial growth of $\mathrm{CaF}_{2}$ on GaAs (100), J. Vac. Sci. Technol. A, 3 (1985) 842-845.

26. E. Daran, L.E. Bausa, A. Muñoz-Yagüe, C. Fontaine, $\mathrm{Er}^{3+}$ doping of $\mathrm{CaF}_{2}$ layers grown by molecular beam epitaxy, Appl. Phys. Lett. 62 (1993) 2616-2618.

27. F. Lahoz, E. Daran, G. Lifante, T. Balaji, A. Muñoz-Yagüe, $\mathrm{CaF}_{2}: \mathrm{Yb}^{3+}+\mathrm{Pr}^{3+}$ codoped waveguides grown by molecular beam epitaxy for $1.3 \mu \mathrm{m}$ applications, Appl. Phys. Lett. 74 (1999) 1060-1062. 28. T. Balaji, G. Lifante, E. Daran, R. Legros, G. Lacoste, Growth by molecular beam epitaxy and characterization of $\mathrm{CaF}_{2}: \mathrm{Pr}^{3+}$ planar waveguides, Thin Solid Films 339 (1999) 187-193.

29. L.E. Bausa, R. Legros, A. Muñoz-Yagüe, $\mathrm{Nd}^{3+}$ incorporation in $\mathrm{CaF}_{2}$ layers grown by molecular beam epitaxy, Appl. Phys. Lett. 59 (1991) 152-154.

30. A. Peña, P. Camy, A. Benayad, J.-L. Doualan, C. Maurel, M. Olivier, V. Nazabal, R. Moncorgé, $\mathrm{Yb}: \mathrm{CaF}_{2}$ grown by liquid phase epitaxy, Opt. Mater. 33 (2011) 1616-1620.

31. S. Renard, P. Camy, J. L. Doualan, R. Moncorgé, M. Couchaud, B. Ferrand, $\mathrm{Tm}^{3+}: \mathrm{CaF}_{2}$ planar waveguides grown by liquid phase epitaxy on $\mathrm{CaF}_{2}$ substrates showing signal enhancement at 1.92 $\mu \mathrm{m}$, Opt. Mater. 28 (2006) 1289-1291.

32. G. Brasse, P. Loiko, C. Grygiel, P. Leprince, A. Benayad, F. Lemarie, J.L. Doualan, A. Braud, P. Camy, Liquid Phase Epitaxy growth of $\mathrm{Tm}^{3+}$-doped $\mathrm{CaF}_{2}$ thin-films based on LiF solvent, J. Alloy Compd. 803 (2019) 442-449.

33. R. Soulard, M. Salhi, G. Brasse, P. Loiko, J.-L. Doualan, L. Guillemot, A. Braud, A. Tyazhev, A. Hideur, P. Camy, Laser operation of highly-doped Tm:LiYF 4 epitaxies: towards thin-disk lasers, Opt. Express 27 (2019) 9287-9301. 
34. P.W. Sullivan, R.F.C. Farrow, G.R. Jones, Insulating epitaxial films of $\mathrm{BaF}_{2}, \mathrm{CaF}_{2}$ and $\mathrm{Ba}_{\mathrm{x}} \mathrm{Ca}_{1-\mathrm{x}} \mathrm{F}_{2}$ grown by MBE on InP substrates, J. Cryst. Growth 60 (1982) 403-413.

35. S. Siskos, C. Fontaine, A. Munoz-Yague, Epitaxial growth of lattice-matched $\mathrm{Ca}_{\mathrm{x}} \mathrm{Sr}_{1-\mathrm{x}} \mathrm{F}_{2}$ on (100) and (110) GaAs substrates, J. Appl. Phys. 56 (1984) 1642-1646.

36. T. Minemura, J. Asano, K. Tsutsui, S. Furukawa, Influence of off-oriented substrates on the crystallinity of $(\mathrm{Ca}, \mathrm{Sr}) \mathrm{F}_{2}$ layers grown on Si (100), Appl. Phys. Lett. 56 (1990) 2198-2200.

37. J.P. Russell, The Raman spectrum of calcium fluoride, Proc. Phys. Soc. 85 (1965) 194.

38. M. Mujaji, J.D. Comins, A Raman study of the superionic behaviour of $\mathrm{CaF}_{2}$ crystals containing trivalent lanthanide ions, Phys. Status Solidi C 4 (2007) 851-855.

39. A.R. Gee, D.C. O'Shea, H.Z. Cummins, Raman scattering and fluorescence in calcium fluoride, Solid State Commun. 4 (1966) 43-46.

40. A.R. Evans, D.B. Fitchen, Raman spectra of alkali fluoride crystals, Solid State Commun. 8 (1970) 537-539.

41. K.P. Jain, S. Radhakrishna, A.K. Prabhakaran, Raman-scattering studies in LiF crystals containing manganese, Phys. Rev. B 5 (1972) 2325-2328.

42. V. Petit, P. Camy, J.L. Doualan, X. Portier, R. Moncorgé, Spectroscopy of $\mathrm{Yb}^{3+}: \mathrm{CaF}_{2}$ : From isolated centers to clusters, Phys. Rev. B 78 (2008) 085131.

43. B. Lacroix, C. Genevois, J.L. Doualan, G. Brasse, A. Braud, P. Ruterana, P. Camy, E. Talbot, R. Moncorgé, J. Margerie, Direct imaging of rare-earth ion clusters in $\mathrm{Yb}: \mathrm{CaF}_{2}$, Phys. Rev. B 90 (2014) 125124.

44. N.M. Strickland, G.D. Jones, Site-selective spectroscopy of $\mathrm{Tm}^{3+}$ centers in $\mathrm{CaF}_{2}: \mathrm{Tm}^{3+}$, Phys. Rev. B 56 (1997) 10916-10929.

45. M.E. Doroshenko, K.A. Pierpoint, O.K. Alimov, A.G. Papashvili, V.A. Konyushkin, A.N. Nakladov, Formation of Tm-Y centers in $\mathrm{CaF}_{2}-\mathrm{YF}_{3}: \mathrm{Tm}^{3+}$ solid-solution crystals, J. Lumin. 208 (2019) 475-478.

46. B.R. Judd, Optical absorption intensities of rare-earth ions, Phys. Rev. 127 (1962) 750-761.

47. G.S. Ofelt, Intensities of crystal spectra of rare-earth ions, J. Chem. Phys. 37 (1962) $511-$ 520.

48. P.S. Peijzel, P. Vergeer, A. Meijerink, M.F. Reid, L.A. Boatner, G.W. Burdick, $4 \mathrm{f}^{\mathrm{n}-1} 5 \mathrm{~d} \rightarrow 4 \mathrm{f}^{\mathrm{n}}$ emission of $\mathrm{Ce}^{3+}, \mathrm{Pr}^{3+}, \mathrm{Nd}^{3+}, \mathrm{Er}^{3+}$, and $\mathrm{Tm}^{3+}$ in $\mathrm{LiYF}_{4}$ and $\mathrm{YPO}_{4}$, Phys. Rev. B 71 (2005) 045116-1-9. 49. L. Zhang, H. Lin, G. Zhang, X. Mateos, J. M. Serres, M. Aguiló, F. Díaz, U. Griebner, V. Petrov, Y. Wang, P. Loiko, E. Vilejshikova, K. Yumashev, Z. Lin, W. Chen, Crystal growth, optical spectroscopy and laser action of $\mathrm{Tm}^{3+}$-doped monoclinic magnesium tungstate, Opt. Express 25 (2017) 3682-3693.

50. A.A. Kornienko, A.A. Kaminskii, E.B. Dunina, Dependence of the line strength of $\mathrm{f}-\mathrm{f}$ transitions on the manifold energy. II. Analysis of $\mathrm{Pr}^{3+}$ in $\mathrm{KPrP}_{4} \mathrm{O}_{12}$, Phys. Status Solidi B 157 (1990) 267-273. 51. P. Loiko, A. Volokitina, X. Mateos, E. Dunina, A. Kornienko, E. Vilejshikova, M. Aguilo, F. Diaz, Spectroscopy of $\mathrm{Tb}^{3+}$ ions in monoclinic $\mathrm{KLu}\left(\mathrm{WO}_{4}\right)_{2}$ crystal: application of an intermediate configuration interaction theory, Opt. Mater. 78 (2018) 495-501.

52. F. Yue, P. Loiko, M. Chen, J.M. Serres, Y. Wang, J. Li, L. Basyrova, E. Dunina, A. Kornienko, L. Fomicheva, S. Dai, Z. Chen, J.E. Bae, T.G. Park, F. Rotermund, V. Jambunathan, A. Lucianetti, T. Mocek, M. Aguiló, F. Díaz, U. Griebner, V. Petrov, X. Mateos, Spectroscopy and diode-pumped laser operation of transparent $\mathrm{Tm}: \mathrm{Lu}_{3} \mathrm{Al}_{5} \mathrm{O}_{12}$ ceramics produced by solid-state sintering, Opt. Express 28 (2020) 28399-28413.

53. N.M. Strickland, G.D. Jones, Site-selective spectroscopy of $\mathrm{Tm}^{3+}$ centers in $\mathrm{CaF}_{2}: \mathrm{Tm}^{3+}$, Phys. Rev. B 56 (1997) 10916-10929. 
54. S. Renard, Synthèse, spectroscopie sélective et fonctionnement laser de $\mathrm{CaF}_{2}: \mathrm{Tm}^{3+}$ sous forme massive et en couches minces, PhD thesis, Universite de Caen, 2005.

55. F.A. Cotton, Chemical applications of group theory, $3^{\text {rd }}$ Ed., Wiley, New York, 1963.

56. M. L. Falin, K. I. Gerasimov, V. A. Latypov, A. M. Leushin, H. Bill, D. Lovy, EPR and optical spectroscopy of $\mathrm{Yb}^{3+}$ ions in $\mathrm{CaF}_{2}$ and $\mathrm{SrF}_{2}$," J. Lumin. 102-103 (2003) 239-242.

57. H. Kühn, S. T. Fredrich-Thornton, C. Kränkel, R. Peters, K. Petermann, Model for the calculation of radiation trapping and description of the pinhole method, Opt. Lett. 32 (2007) 1908-1910.

58. P. Loiko, M. Pollnau, Stochastic model of energy-transfer processes among rare-earth ions. Example of $\mathrm{Al}_{2} \mathrm{O}_{3}: \mathrm{Tm}^{3+}$, J. Phys. Chem. C 20 (2016) 26480-26489.

59. A. Albalawi, S. Varas, A. Chiasera, H. Gebavi, W. Albalawi, W. Blanc, R. Balda, A. Lukowiak,

M. Ferrari, S. Taccheo, Determination of reverse cross-relaxation process constant in Tm-doped glass by ${ }^{3} \mathrm{H}_{4}$ fluorescence decay tail fitting, Opt. Mater. Express 7 (2017) 3760-3768.

60. B. F. Aull, H. P. Jenssen, Vibronic interactions in Nd:YAG resulting in nonreciprocity of absorption and stimulated emission cross sections, IEEE J. Quantum Electron. 18 (1982) 925-930.

61. D.S. Moore, J.C. Wright, Laser spectroscopy of defect chemistry in $\mathrm{CaF}_{2}: \mathrm{Er}^{3+}$, J. Chem. Phys. 74 (1981) 1626-1636.

62. G.D. Jones, R.J. Reeves, $\mathrm{Na}^{+}, \mathrm{Li}^{+}$and cubic centres in rare-earth-doped $\mathrm{CaF}_{2}$ and $\mathrm{SrF}_{2}$, J. Lumin. 87 (2000) 1108-1111.

63. L. Su, J. Xu, H. Li, L. Wen, Y. Zhu, Z. Zhao, Y. Dong, G. Zhou, J. Si, Sites structure and spectroscopic properties of $\mathrm{Yb}$-doped and $\mathrm{Yb}, \mathrm{Na}$-codoped $\mathrm{CaF}_{2}$ laser crystals, Chem. Phys. Lett. 406 (2005) 254-258.

64. E. Daran, R. Legros, A. Muñoz-Yagüe, C. Fontaine, L.E. Bausá, Effect of growth temperature and doping concentration on the distribution of the emitting centers in $\mathrm{CaF}_{2}:$ Er molecular beam epitaxial layers, J. Appl. Phys. 75 (1994) 2749-2752.

65. L.E. Bausa, R. Legros, A. Muñoz-Yagüe, Effect of $\mathrm{Nd}^{3+}$ concentration on the emission spectra of $\mathrm{CaF}_{2}$ :Nd layers grown by molecular-beam epitaxy, J. Appl. Phys. 70 (1991) 4485-4489.

66. V. V. Osiko, I. A. Shcherbakov, Calculation of point-defect equilibrium in $\mathrm{CaF}_{2}-\mathrm{NdF}_{3}$ crystals, Sov. Phys. Solid State 14 (1971) 820.

67. G. Dražić, S. Kobe, A.C. Cefalas, E. Sarantopoulou, Z. Kollia, Observation of nanostructured cluster formation of Tm ions in $\mathrm{CaF}_{2}$ crystals, Mater. Sci. Eng. B 152 (2008) 119-124. 


\section{List of figure captions}

Figure 1. Scanning Electron Microscope (SEM) images of the LPE-grown $\sim 6$ at.\% $\mathrm{Tm}: \mathrm{CaF}_{2}$ film (top view): (a-c) raw (as-grown) film surface observed with different magnifications, (d) crazing of polished film.

Figure 2. Scanning Electron Microscope (SEM) image of the side surface of the $\sim 6$ at.\% Tm: $\mathrm{CaF}_{2} / \mathrm{CaF}_{2}$ epitaxy.

Figure 3. (a) Element distribution across the end-facet of the $\sim 6$ at. $\% \mathrm{Tm}: \mathrm{CaF}_{2} / \mathrm{CaF}_{2}$ epitaxy analyzed by EDX spectroscopy. All profiles are normalized to unity and shifted along the vertical axis; (b) EDX mapping of Tm.

Figure 4. Confocal laser microscope study of the $\sim 6$ at. $\%$ Tm:CaF$/ \mathrm{CaF}_{2}$ epitaxy: $(\mathrm{a}, \mathrm{b})$ top view: (a) raw surface after removing the residual solvent, (b) polished surface; (c,d): side view: (c) without polarizers, (d) in crossed polarizers. Transmission mode, $\lambda=405$ $\mathrm{nm}$.

Figure 5. Unpolarized RT $\mu$-Raman spectra measured from the top (raw, as-grown) and side (polished) surfaces of the $\sim 6$ at. $\% \mathrm{Tm}: \mathrm{CaF}_{2} / \mathrm{CaF}_{2}$ epitaxy, numbers denote the Raman frequencies in $\mathrm{cm}^{-1}$, asterisks mark the peaks due to the $\mathrm{Tm}^{3+}$ luminescence, $\lambda_{\mathrm{exc}}=488.0 \mathrm{~nm}$. The spectrum for $\mathrm{LiF}$ is given for comparison.

Figure 6. RT absorption of $\mathrm{Tm}^{3+}$ ions in LPE-grown $\mathrm{Tm}: \mathrm{CaF}_{2}$ thin-films: (a) an overview absorption spectrum for a $\sim 6$ at.\% Tm-doped film; (b,c) absorption crosssections, $\sigma_{\text {abs }}$, for the (b) ${ }^{3} \mathrm{H}_{6} \rightarrow{ }^{3} \mathrm{H}_{4}$ and (c) ${ }^{3} \mathrm{H}_{6} \rightarrow{ }^{3} \mathrm{~F}_{4}$ transitions of $\mathrm{Tm}^{3+}$ ions; the spectra for bulk $\mathrm{Tm}: \mathrm{CaF}_{2}$ crystals are given for comparison.

Figure 7. RT excitation spectra for the LPE-grown $\mathrm{Tm}: \mathrm{CaF}_{2}$ thin-films, the spectra for bulk crystals are given for comparison, $\lambda$ lum $=1810 \mathrm{~nm}$.

Figure 8. LT $(12 \mathrm{~K})$ absorption spectra of LPE-grown $\sim 6$ at. $\% \mathrm{Tm}: \mathrm{CaF}_{2}$ thin-films, the spectra for bulk 1.5 at.\% Tm: $\mathrm{CaF}_{2}$ crystal are given for comparison. Transitions: (a) ${ }^{3} \mathrm{H}_{6} \rightarrow{ }^{3} \mathrm{~F}_{4}$, (b) ${ }^{3} \mathrm{H}_{6} \rightarrow{ }^{3} \mathrm{H}_{5}$, (c) ${ }^{3} \mathrm{H}_{6} \rightarrow{ }^{3} \mathrm{H}_{4}$ and (d) ${ }^{3} \mathrm{H}_{6} \rightarrow{ }^{3} \mathrm{~F}_{2,3}$. $\mathrm{O}^{2-}$ mark peaks assigned to oxygen-assisted sites (after [54]), $\mathrm{O}_{\mathrm{h}}-$ to cubic sites.

Figure 9. Near-IR RT luminescence of $\mathrm{Tm}^{3+}$ ions in LPE-grown $\mathrm{Tm}: \mathrm{CaF}_{2}$ thin-films: (a) overview spectra for the $\sim 2$ at. $\%$ and $\sim 6$ at. $\% \mathrm{Tm}: \mathrm{CaF}_{2}$ layers, the spectra for bulk crystals are given for comparison; (b) a close look at the ${ }^{3} \mathrm{H}_{4} \rightarrow{ }^{3} \mathrm{~F}_{4}$ emission for the $\sim 2$ at. $\% \mathrm{Tm}: \mathrm{CaF}_{2}$ layer. $\lambda_{\mathrm{exc}}=768 \mathrm{~nm}$. 
Figure 10. LT $(12 \mathrm{~K})$ luminescence spectra of $\mathrm{Tm}: \mathrm{CaF}_{2}$ epitaxial layers and bulk crystals corresponding to the ${ }^{3} \mathrm{~F}_{4} \rightarrow{ }^{3} \mathrm{H}_{6} \mathrm{Tm}^{3+}$ transition measured under spectrallyselective excitation: (a) epitaxy, $\sim 2$ at. $\% \mathrm{Tm}$, (b) bulk crystal, 0.05 at.\% Tm, (c) epitaxy, $\sim 6$ at\% Tm and (d) bulk crystal, 4.5 at.\% Tm. Grey curves - RT emission spectra (measured under non-selective excitation), vertical dashes - theoretical positions of electronic transitions for $\mathrm{Tm}^{3+}$ ions in $\mathrm{C}_{3 \mathrm{v}}, \mathrm{C}_{4 \mathrm{v}}$ and $\mathrm{C}_{3 \mathrm{v}}\left(\mathrm{T}_{2}\right)$ sites in $\mathrm{CaF}_{2}$.

Figure 11. LT (12 K) luminescence spectra of (a) 2 at.\% Tm: $\mathrm{CaF}_{2}$ epitaxial layer and (b) 0.05 at.\% Tm:CaF2 bulk crystal corresponding to the ${ }^{3} \mathrm{H}_{4} \rightarrow{ }^{3} \mathrm{~F}_{4} \mathrm{Tm}^{3+}$ transition measured under spectrally-selective excitation. Grey curves - RT emission spectra (measured under non-selective excitation), vertical dashes - theoretical positions of electronic transitions for $\mathrm{Tm}^{3+}$ ions in $\mathrm{C}_{3 \mathrm{v}}, \mathrm{C}_{4 \mathrm{v}}$ and $\mathrm{C}_{3 \mathrm{v}}\left(\mathrm{T}_{2}\right)$ sites in $\mathrm{CaF}_{2}$.

Figure 12. RT luminescence decay curves for LPE-grown polished $\mathrm{Tm}: \mathrm{CaF}_{2}$ thinfilms: (a) emission from the ${ }^{3} \mathrm{~F}_{4}$ state, $\lambda_{\text {lum }}=1830 \mathrm{~nm}$; (c,d) emission from the ${ }^{3} \mathrm{H}_{4}$ state, $\lambda_{\text {lum }}=809 \mathrm{~nm} . \lambda_{\text {exc }}=765 \mathrm{~nm}$. In (a), the decay curve measured from the raw (as-grown) surface of the epitaxy is shown for comparison.

Figure 13. RT emission properties of $\mathrm{Tm}^{3+}$ ions in LPE-grown $\sim 6$ at. $\% \mathrm{Tm}: \mathrm{CaF}_{2}$ thinfilms: (a) stimulated-emission cross-sections, $\sigma$ SE, for the ${ }^{3} \mathrm{~F}_{4} \rightarrow{ }^{3} \mathrm{H}_{6}$ transition; the spectrum for bulk crystal is given for comparison; (b) gain cross-section, $\sigma \mathrm{g}=\beta \sigma \mathrm{SE}-(1$ $-\beta) \sigma_{\mathrm{abs}}$, spectra for various inversion ratios $\beta=N_{2}\left({ }^{3} \mathrm{~F}_{4}\right) / N_{\mathrm{Tm}}$.

Figure 14. Near-field profile of the guided pump mode at $770 \mathrm{~nm}$ for the $\mathrm{Tm}: \mathrm{CaF}_{2} /$ $\mathrm{CaF}_{2}$ epitaxy, white lines mark layer / substrate and layer / air interfaces. 

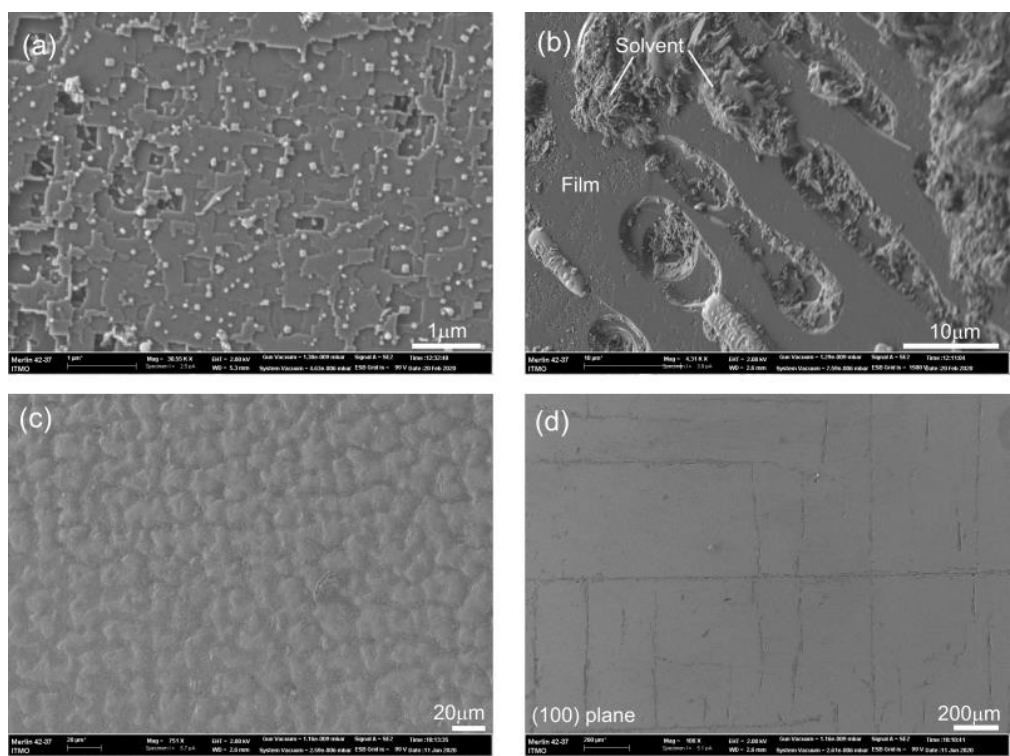

Figure 1. Scanning Electron Microscope (SEM) images of the LPE-grown $\sim 6$ at.\% $\mathrm{Tm}: \mathrm{CaF}_{2}$ film (top view): (a-c) raw (as-grown) film surface observed with different magnifications, (d) crazing of polished film.

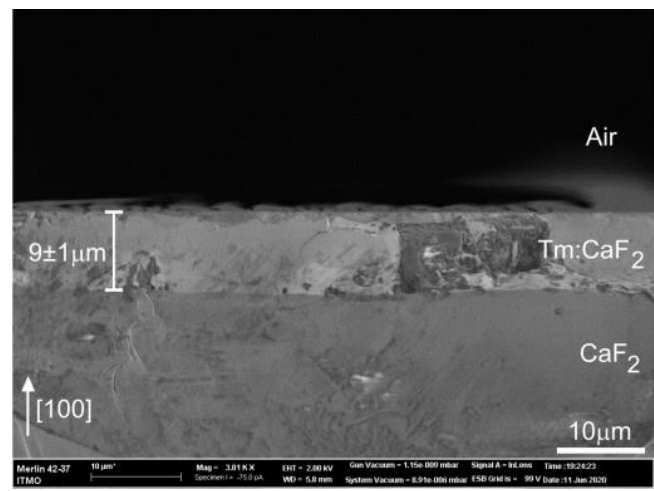

Figure 2. Scanning Electron Microscope (SEM) image of the side surface of the $\sim 6$ at.\% $\mathrm{Tm}: \mathrm{CaF}_{2} / \mathrm{CaF}_{2}$ epitaxy. 

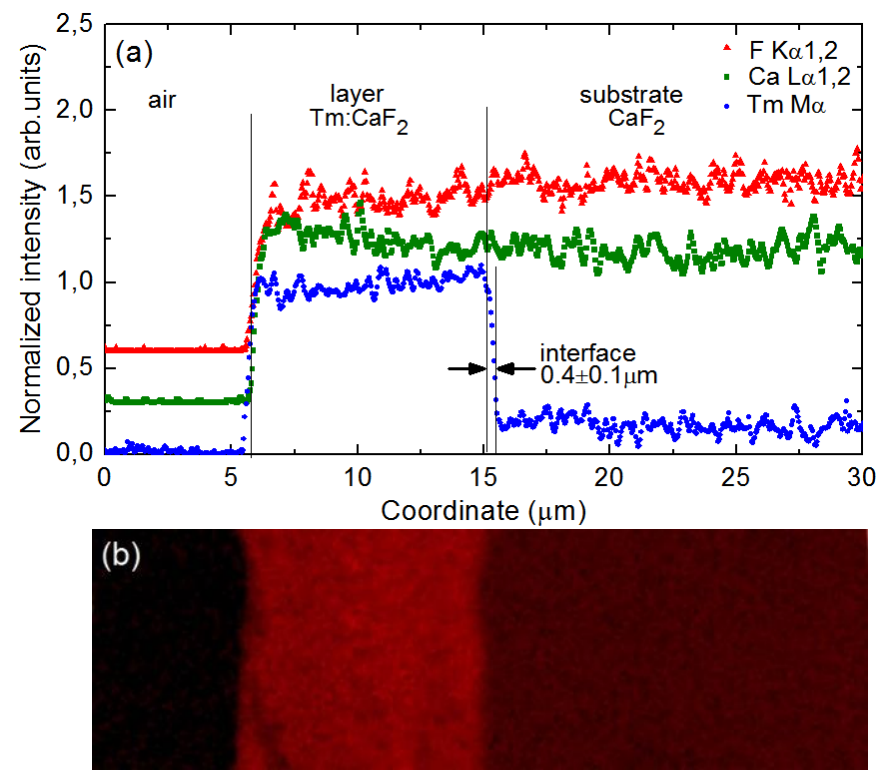

Figure 3. (a) Element distribution across the end-facet of the $~ 6$ at. $\% \mathrm{Tm}: \mathrm{CaF}_{2} / \mathrm{CaF}_{2}$ epitaxy analyzed by EDX spectroscopy. All profiles are normalized to unity and shifted along the vertical axis; (b) EDX mapping of Tm.
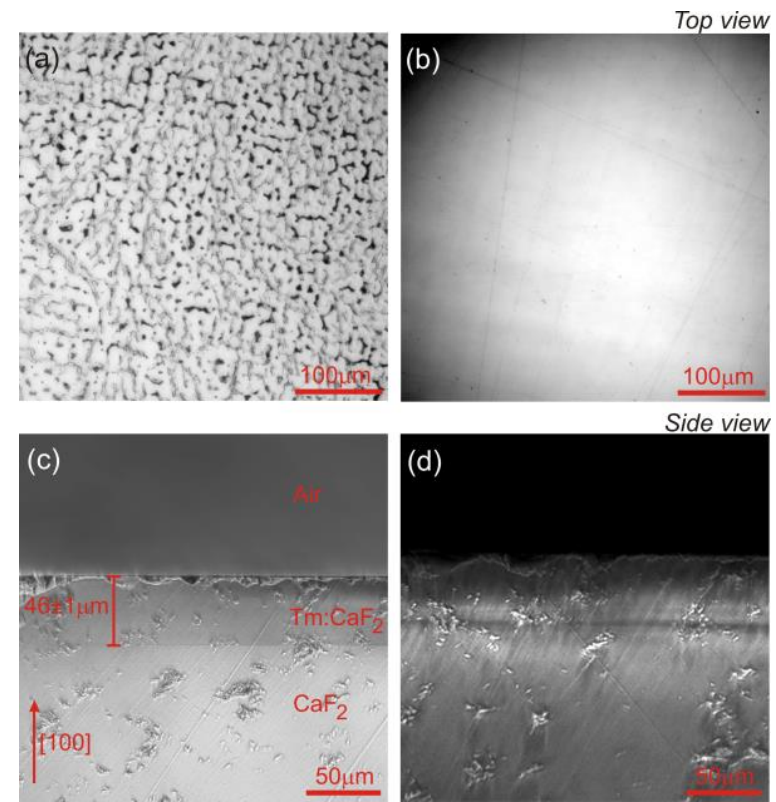

Figure 4. Confocal laser microscope study of the $\sim 6$ at. $\% \mathrm{Tm}: \mathrm{CaF}_{2} / \mathrm{CaF}_{2}$ epitaxy: $(a, b)$ top view: (a) raw surface after removing the residual solvent, (b) polished surface; (c,d): side view: (c) without polarizers, (d) in crossed polarizers. Transmission mode, $\lambda=405 \mathrm{~nm}$. 


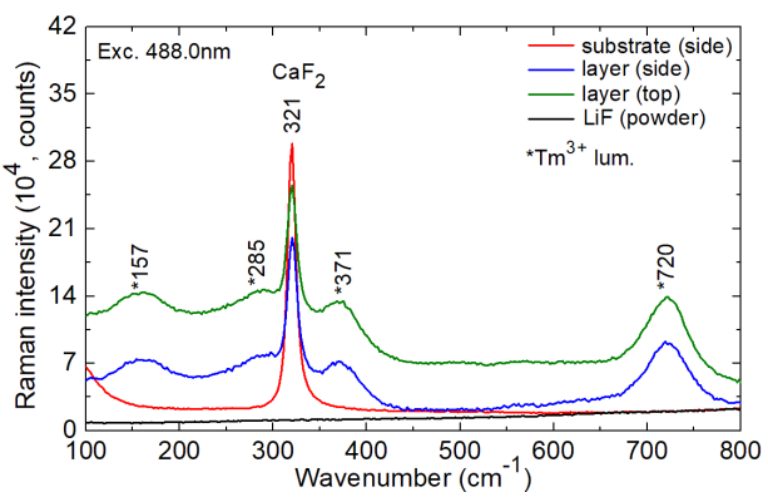

Figure 5. Unpolarized RT $\mu$-Raman spectra measured from the top (raw, as-grown) and side (polished) surfaces of the $\sim 6$ at. $\% \mathrm{Tm}: \mathrm{CaF}_{2} / \mathrm{CaF}_{2}$ epitaxy, numbers denote the Raman frequencies in $\mathrm{cm}^{-1}$, asterisks mark the peaks due to the $\mathrm{Tm}^{3+}$ luminescence, $\lambda_{\mathrm{exc}}=488.0 \mathrm{~nm}$. The spectrum for LiF is given for comparison.
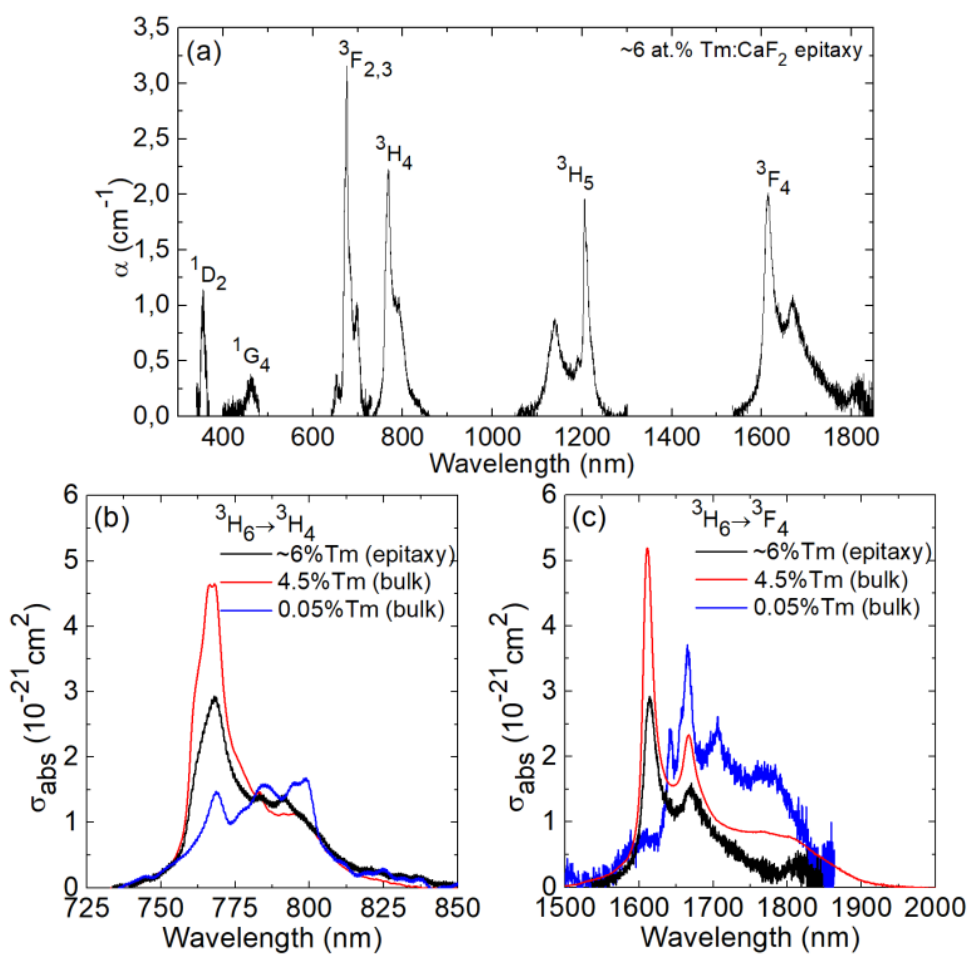

Figure 6. RT absorption of $\mathrm{Tm}^{3+}$ ions in LPE-grown $\mathrm{Tm}: \mathrm{CaF}_{2}$ thin-films: (a) an overview absorption spectrum for a $\sim 6$ at.\% Tm-doped film; (b,c) absorption crosssections, $\sigma_{\mathrm{abs}}$, for the (b) ${ }^{3} \mathrm{H}_{6} \rightarrow{ }^{3} \mathrm{H}_{4}$ and (c) ${ }^{3} \mathrm{H}_{6} \rightarrow{ }^{3} \mathrm{~F}_{4}$ transitions of $\mathrm{Tm}^{3+}$ ions; the spectra for bulk $\mathrm{Tm}: \mathrm{CaF}_{2}$ crystals are given for comparison. 


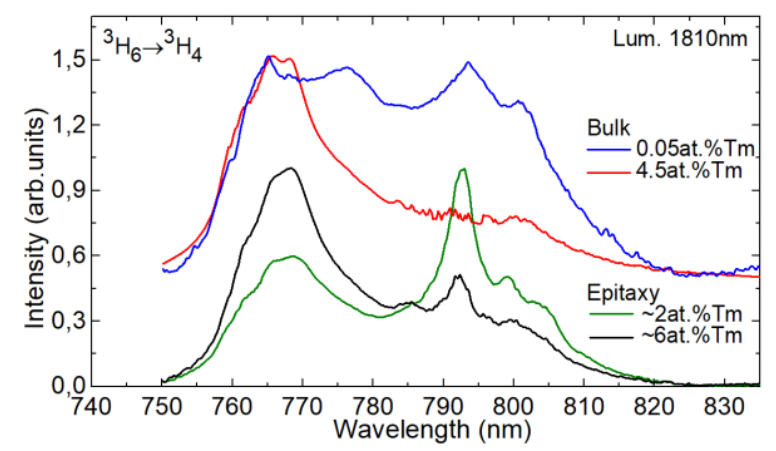

Figure 7. RT excitation spectra for the LPE-grown Tm: $\mathrm{CaF}_{2}$ thin-films, the spectra for bulk crystals are given for comparison, $\lambda_{\text {lum }}=1810 \mathrm{~nm}$.
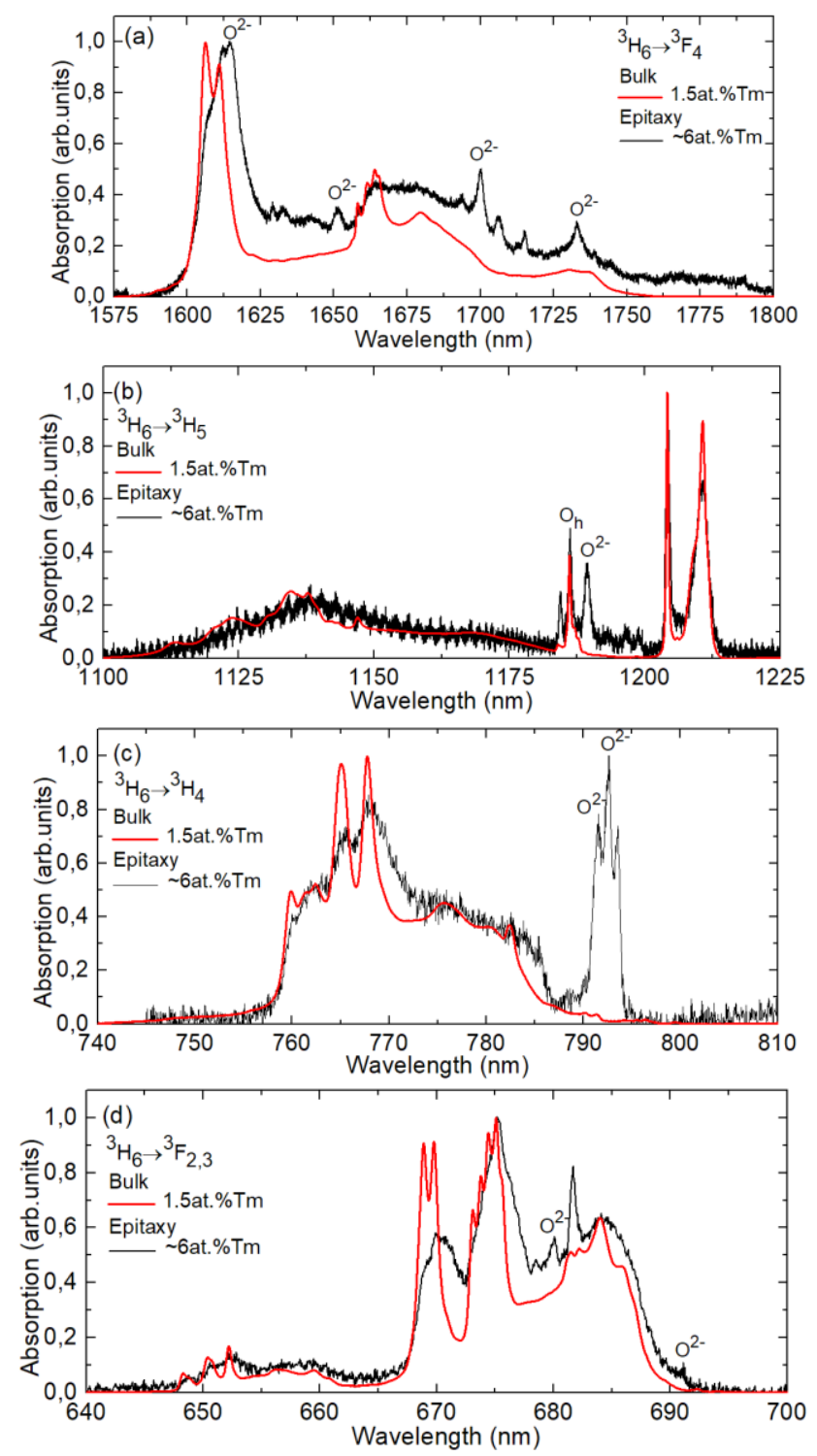

Figure 8. LT (12 K) absorption spectra of LPE-grown 6 at.\% $\mathrm{Tm}_{\mathrm{CaF}}$ thin-films, the spectra for bulk 1.5 at.\% Tm: $\mathrm{CaF}_{2}$ crystal are given for comparison. Transitions: (a) ${ }^{3} \mathrm{H}_{6} \rightarrow{ }^{3} \mathrm{~F}_{4}$, (b) ${ }^{3} \mathrm{H}_{6} \rightarrow{ }^{3} \mathrm{H}_{5}$, (c) ${ }^{3} \mathrm{H}_{6} \rightarrow{ }^{3} \mathrm{H}_{4}$ and $(\mathrm{d}){ }^{3} \mathrm{H}_{6} \rightarrow{ }^{3} \mathrm{~F}_{2,3}$. $\mathrm{O}^{2-}$ mark peaks assigned to oxygen-assisted sites (after [54]), $\mathrm{O}_{\mathrm{h}}-$ to cubic sites. 

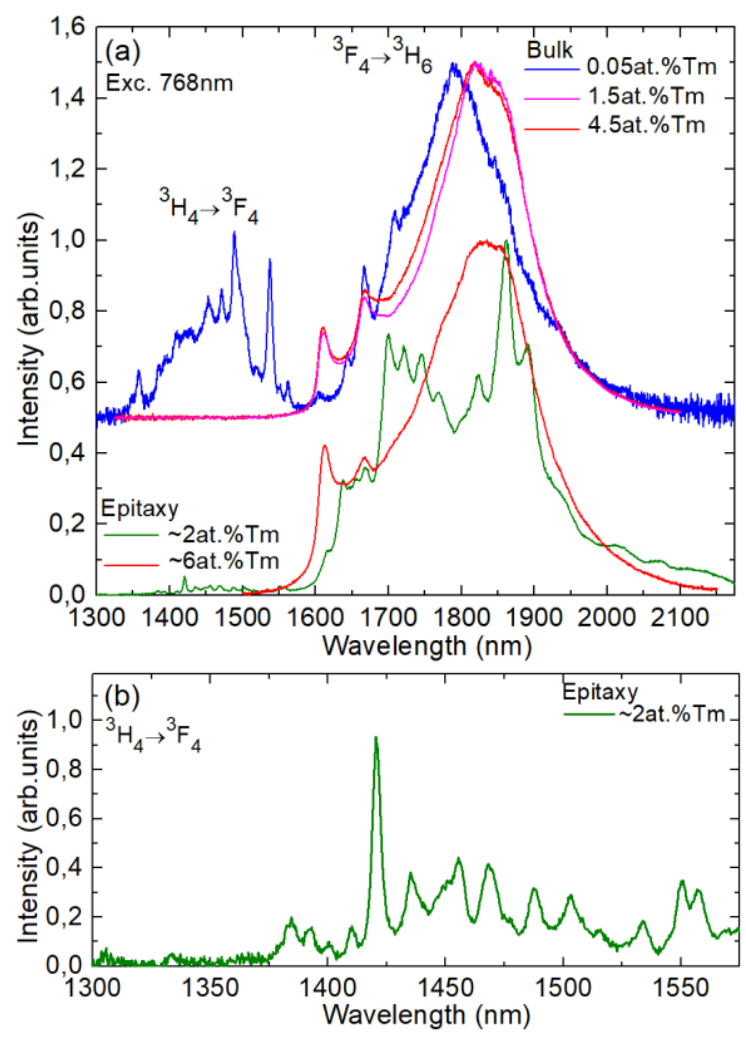

Figure 9. Near-IR RT luminescence of $\mathrm{Tm}^{3+}$ ions in LPE-grown Tm:CaF 2 thin-films: (a) overview spectra for the $\sim 2$ at. $\%$ and $\sim 6$ at.\% $\mathrm{Tm}_{\mathrm{CaF}}$ layers, the spectra for bulk crystals are given for comparison; (b) a close look at the ${ }^{3} \mathrm{H}_{4} \rightarrow{ }^{3} \mathrm{~F}_{4}$ emission for the $\sim 2$ at. $\% \mathrm{Tm}: \mathrm{CaF}_{2}$ layer. $\lambda_{\mathrm{exc}}=768 \mathrm{~nm}$. 

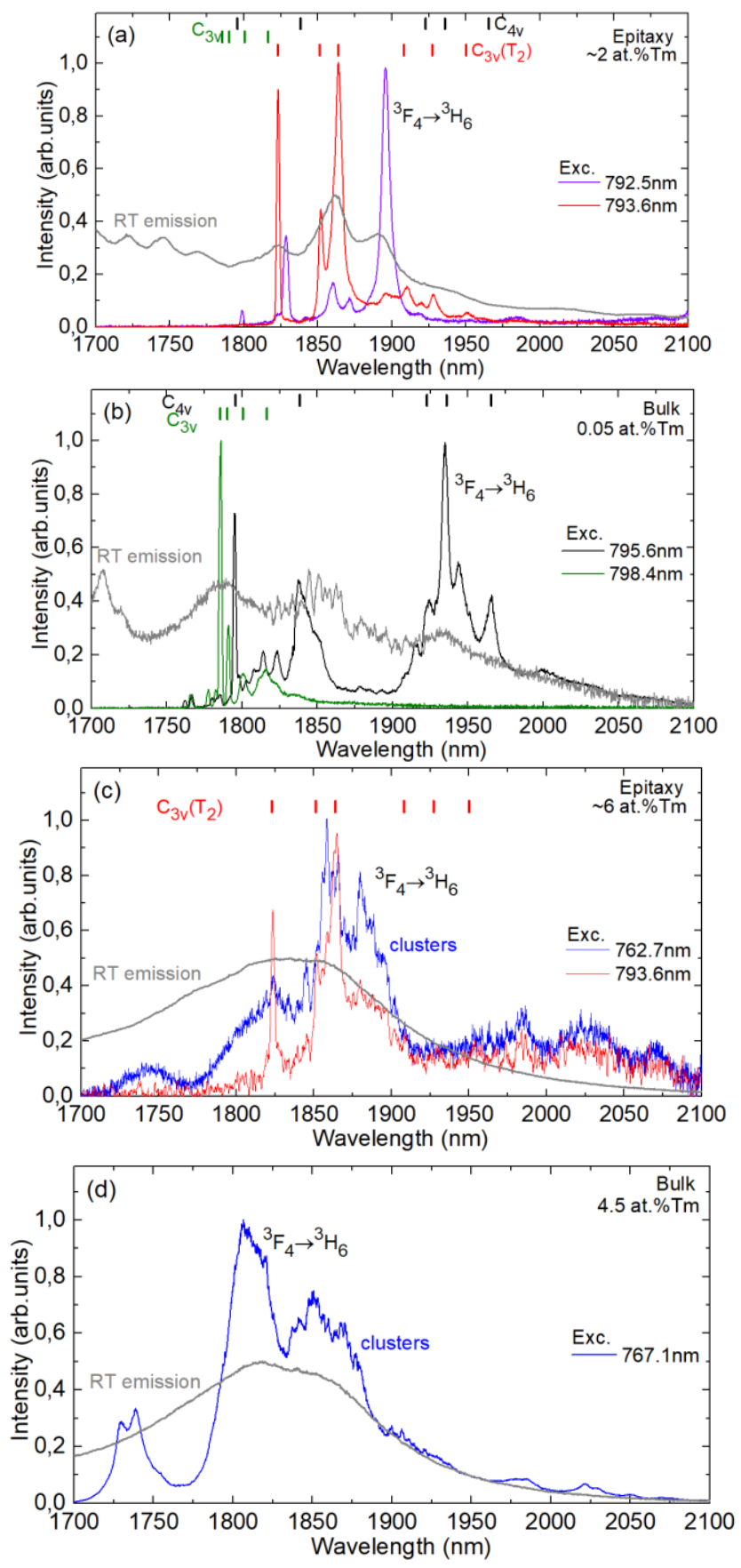

Figure 10. LT $\left(12 \mathrm{~K}\right.$ ) luminescence spectra of $\mathrm{Tm}: \mathrm{CaF}_{2}$ epitaxial layers and bulk crystals corresponding to the ${ }^{3} \mathrm{~F}_{4} \rightarrow{ }^{3} \mathrm{H}_{6} \mathrm{Tm}^{3+}$ transition measured under spectrallyselective excitation: (a) epitaxy, 2 at.\% Tm, (b) bulk crystal, 0.05 at.\% Tm, (c) epitaxy, $\sim 6$ at\% Tm and (d) bulk crystal, 4.5 at.\% Tm. Grey curves - RT emission spectra (measured under non-selective excitation), vertical dashes - theoretical positions of electronic transitions for $\mathrm{Tm}^{3+}$ ions in $\mathrm{C}_{3 v}, \mathrm{C}_{4 v}$ and $\mathrm{C}_{3 v}\left(\mathrm{~T}_{2}\right)$ sites in $\mathrm{CaF}_{2}$. 

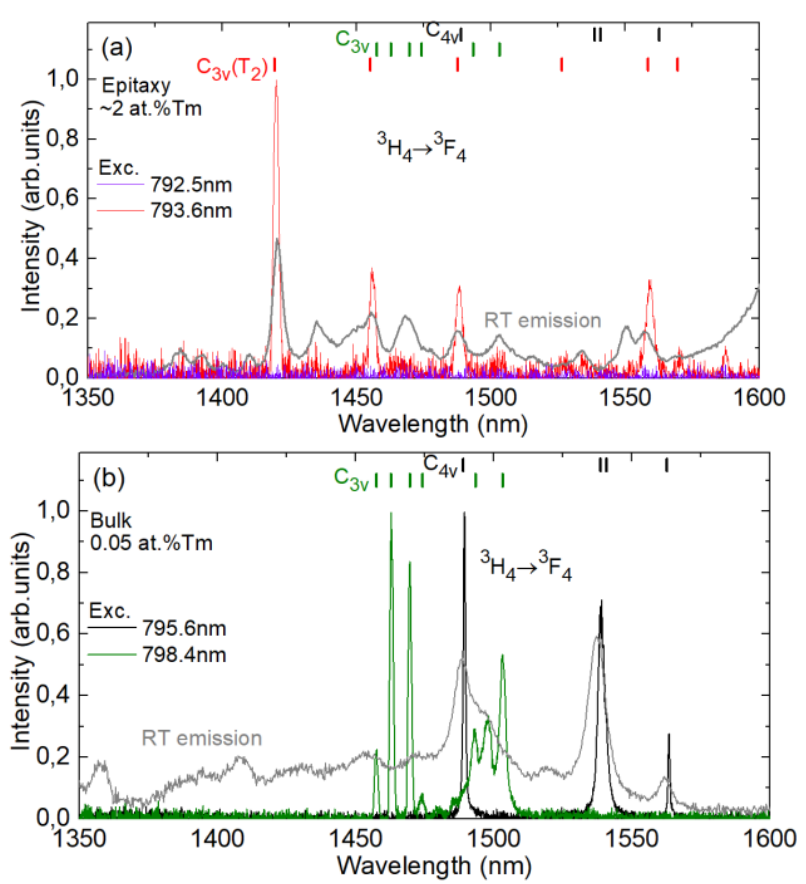

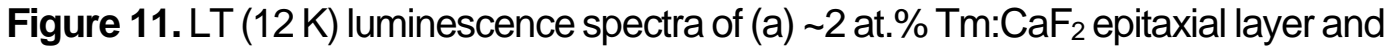
(b) 0.05 at.\% Tm:CaF ${ }_{2}$ bulk crystal corresponding to the ${ }^{3} \mathrm{H}_{4} \rightarrow{ }^{3} \mathrm{~F}_{4} \mathrm{Tm}^{3+}$ transition measured under spectrally-selective excitation. Grey curves - RT emission spectra (measured under non-selective excitation), vertical dashes - theoretical positions of electronic transitions for $\mathrm{Tm}^{3+}$ ions in $\mathrm{C}_{3 v}, \mathrm{C}_{4 v}$ and $\mathrm{C}_{3 v}\left(\mathrm{~T}_{2}\right)$ sites in $\mathrm{CaF}_{2}$.
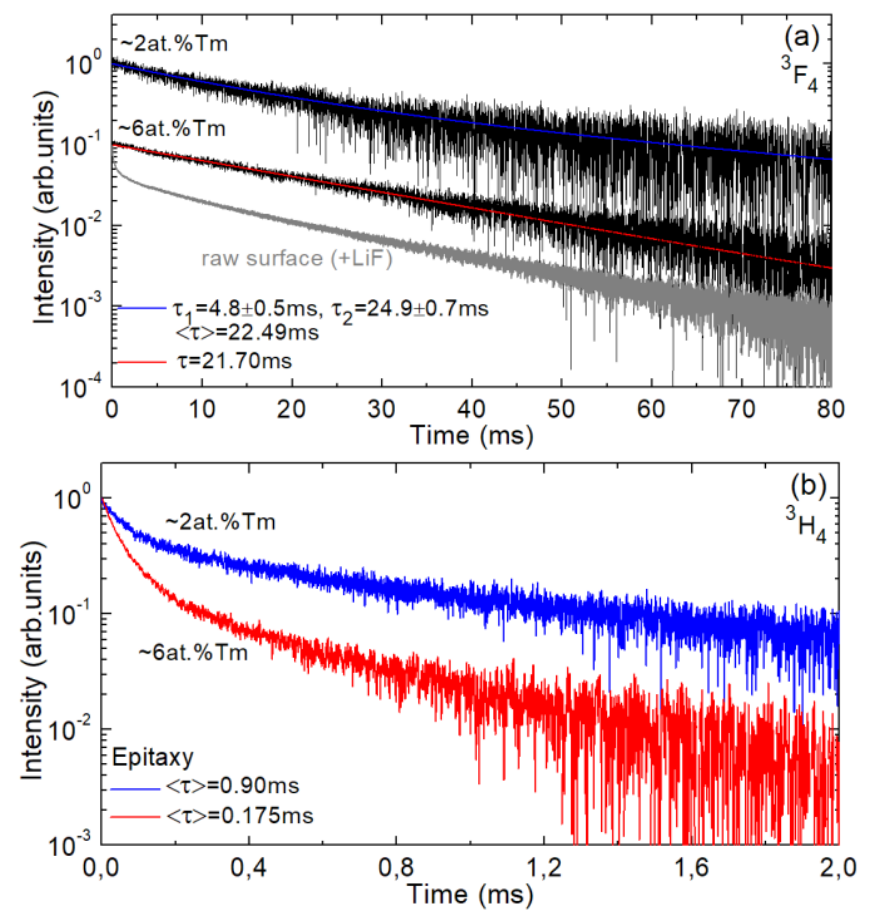

Figure 12. RT luminescence decay curves for LPE-grown polished $\mathrm{Tm}: \mathrm{CaF}_{2}$ thinfilms: (a) emission from the ${ }^{3} \mathrm{~F}_{4}$ state, $\lambda_{\text {lum }}=1830 \mathrm{~nm}$; (c,d) emission from the ${ }^{3} \mathrm{H}_{4}$ state, $\lambda_{\text {lum }}=809 \mathrm{~nm}$. $\lambda_{\text {exc }}=765 \mathrm{~nm}$. In (a), the decay curve measured from the raw (asgrown) surface of the epitaxy is shown for comparison. 

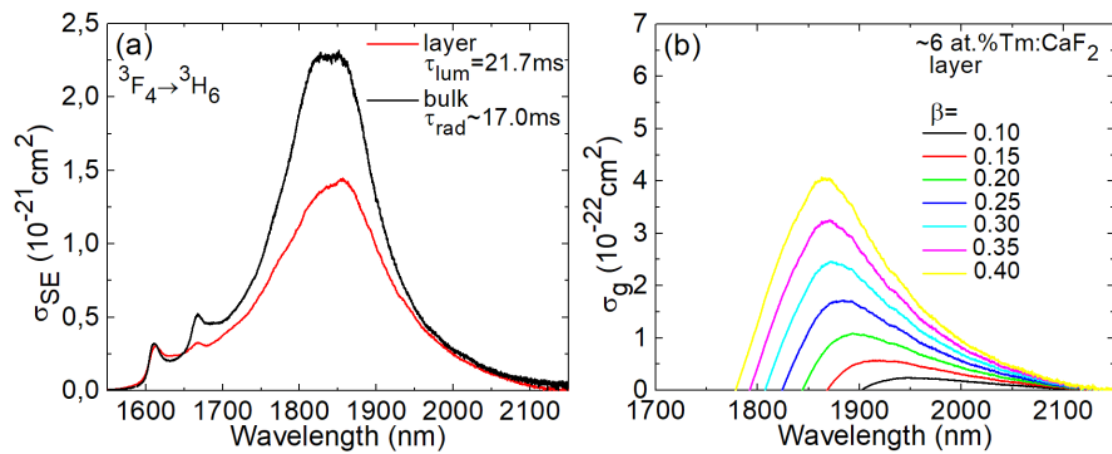

Figure 13. RT emission properties of $\mathrm{Tm}^{3+}$ ions in LPE-grown $\sim 6$ at.\% $\mathrm{Tm}: \mathrm{CaF}_{2}$ thinfilms: (a) stimulated-emission cross-sections, $\sigma_{\mathrm{SE}}$, for the ${ }^{3} \mathrm{~F}_{4} \rightarrow{ }^{3} \mathrm{H}_{6}$ transition; the spectrum for bulk crystal is given for comparison; (b) gain cross-section, $\sigma_{g}=\beta \sigma_{\mathrm{SE}}-$ $(1-\beta) \sigma_{\mathrm{abs}}$, spectra for various inversion ratios $\beta=N_{2}\left({ }^{3} \mathrm{~F}_{4}\right) / N_{\mathrm{Tm}}$.

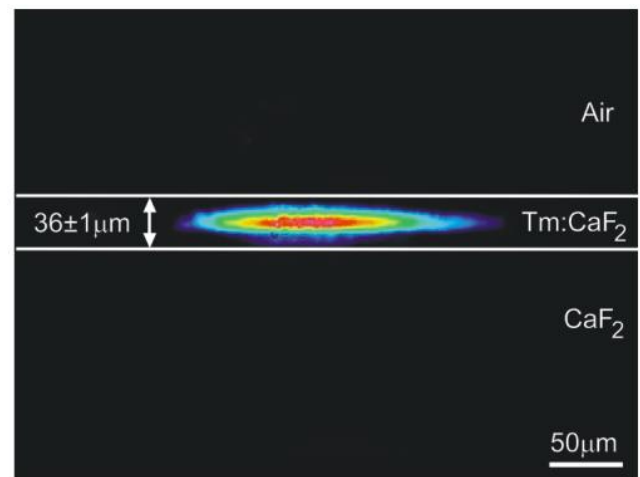

Figure 14. Near-field profile of the guided pump mode at $770 \mathrm{~nm}$ for the $\mathrm{Tm}: \mathrm{CaF}_{2} /$ $\mathrm{CaF}_{2}$ epitaxy, white lines mark layer / substrate and layer / air interfaces. 
Table 3. Probabilities of radiative spontaneous transitions ${ }^{*}$ for $\mathrm{Tm}^{3+}$ ions in the $\sim 6$ at.\% $\mathrm{Tm}^{-\mathrm{CaF}_{2}}$ epitaxial thin-film (as calculated using the $\mathrm{mJ}-\mathrm{O}$ theory).

\begin{tabular}{|c|c|c|c|c|c|c|}
\hline $\begin{array}{l}\text { Excited } \\
\text { state }\end{array}$ & $\begin{array}{l}\text { Terminal } \\
\text { state }\end{array}$ & $\begin{array}{l}\langle\lambda\rangle, \\
\mathrm{nm}\end{array}$ & $\begin{array}{l}A_{\text {calc }}^{\Sigma}(J J), \\
\mathrm{s}^{-1}\end{array}$ & $\begin{array}{l}B(J J), \\
\%\end{array}$ & $\begin{array}{l}A_{\text {lot, }} \\
\mathrm{s}^{-1}\end{array}$ & $\begin{array}{l}T_{\mathrm{rad}}, \\
\mathrm{ms}\end{array}$ \\
\hline${ }^{3} \mathrm{~F}_{4}$ & ${ }^{3} \mathrm{H}_{6}$ & 1640 & $47.0^{\mathrm{ED}}$ & 100 & 47.0 & 21.30 \\
\hline \multirow[t]{2}{*}{${ }^{3} \mathrm{H}_{5}$} & ${ }^{3} \mathrm{~F}_{4}$ & 4246 & $5.17^{\mathrm{ED}}+0.09^{\mathrm{MD}}$ & 3.3 & 160.6 & 6.23 \\
\hline & ${ }^{3} \mathrm{H}_{6}$ & 1183 & $101.8^{\mathrm{ED}}+53.6^{\mathrm{MD}}$ & 96.7 & & \\
\hline \multirow[t]{3}{*}{${ }^{3} \mathrm{H}_{4}$} & ${ }^{3} \mathrm{H}_{5}$ & 2283 & $16.3^{\mathrm{ED}}+5.47^{\mathrm{MD}}$ & 2.4 & 902.0 & 1.11 \\
\hline & ${ }^{3} \mathrm{~F}_{4}$ & 1485 & $82.5^{\mathrm{ED}}+12.1^{\mathrm{MD}}$ & 10.5 & & \\
\hline & ${ }^{3} \mathrm{H}_{6}$ & 779.3 & $785.6^{\mathrm{ED}}$ & 87.1 & & \\
\hline \multirow[t]{4}{*}{${ }^{3} F_{3}$} & ${ }^{3} \mathrm{H}_{4}$ & 5447 & $2.18^{\mathrm{ED}}$ & 0.1 & 1924.9 & 0.52 \\
\hline & ${ }^{3} \mathrm{H}_{5}$ & 1608 & $206.2^{\mathrm{ED}}$ & 10.7 & & \\
\hline & ${ }^{3} \mathrm{~F}_{4}$ & 1166 & $77.7^{\mathrm{ED}}+30.6^{\mathrm{MD}}$ & 5.6 & & \\
\hline & ${ }^{3} \mathrm{H}_{6}$ & 681.7 & $1608.2^{\mathrm{ED}}$ & 83.5 & & \\
\hline \multirow[t]{5}{*}{${ }^{3} \mathrm{~F}_{2}$} & ${ }^{3} F_{3}$ & 15106 & $0.08^{\mathrm{ED}}+0.10^{\mathrm{MD}}$ & $<0.1$ & 1580.0 & 0.63 \\
\hline & ${ }^{3} \mathrm{H}_{4}$ & 4002 & $15.3^{\mathrm{ED}}$ & 1.0 & & \\
\hline & ${ }^{3} \mathrm{H}_{5}$ & 1454 & $323.5^{\mathrm{ED}}$ & 20.5 & & \\
\hline & ${ }^{3} \mathrm{~F}_{4}$ & 1083 & $485.4^{\mathrm{ED}}$ & 30.7 & & \\
\hline & ${ }^{3} \mathrm{H}_{6}$ & 652.3 & $755.6^{\mathrm{ED}}$ & 47.8 & & \\
\hline \multirow[t]{6}{*}{${ }^{1} G_{4}$} & ${ }^{3} \mathrm{~F}_{2}$ & 1595 & $26.3^{\mathrm{ED}}$ & 0.8 & 3255.3 & 0.31 \\
\hline & ${ }^{3} \mathrm{~F}_{3}$ & 1442 & $156.3^{\mathrm{ED}}+2.62^{\mathrm{MD}}$ & 4.9 & & \\
\hline & ${ }^{3} \mathrm{H}_{4}$ & 1140 & $444.7^{\mathrm{ED}}+20.4^{\mathrm{MD}}$ & 14.3 & & \\
\hline & ${ }^{3} \mathrm{H}_{5}$ & 760.4 & $1388.6^{\mathrm{ED}}+80.2^{\mathrm{MD}}$ & 45.1 & & \\
\hline & ${ }^{3} \mathrm{~F}_{4}$ & 644.9 & $285.5^{\mathrm{ED}}+6.19^{\mathrm{MD}}$ & 9.0 & & \\
\hline & ${ }^{3} \mathrm{H}_{6}$ & 462.9 & $844.4^{\mathrm{ED}}$ & 25.9 & & \\
\hline
\end{tabular}

${ }^{*}\langle\lambda\rangle$ - calculated mean emission wavelength, $A^{\Sigma_{\text {calc }}}$ - probability of radiative spontaneous transitions (ED + MD), $B(\mathrm{JJ})$ - luminescence branching ratio, $A_{\text {tot }}$ and $\tau_{\text {rad }}$ - total probability of radiative spontaneous transitions (ED+MD) and radiative lifetime of the excited state, respectively. ED and MD stand for electric-dipole and magnetic-dipole transitions, respectively. 